\title{
A STUDY OF WORKPLACE ATTRIBUTES: 'PLACE TO WORK' INDEX EXAMINED THROUGH ORGANIZATIONAL PREFERENCE
}

\author{
A Dissertation \\ presented to \\ the Faculty of the Graduate School \\ at the University of Missouri-Columbia \\ In Partial Fulfillment \\ of the Requirements for the Degree \\ Doctor of Philosophy \\ by \\ AMANDA L. ANDRADE \\ Dr. Ronald Phillips, Dissertation Supervisor \\ DECEMBER 2013
}


(c) Copyright by Amanda L. Andrade 2013

All Rights Reserved 
The undersigned, appointed by the Dean of the Graduate School, have examined the thesis entitled

\author{
A STUDY OF WORKPLACE ATTRIBUTES: 'PLACE TO WORK' \\ INDEX EXAMINED THROUGH ORGANIZATIONAL PREFERENCE
}

Presented by Amanda L. Andrade

A candidate for the degree of Doctor of Philosophy

And hereby certify that in their opinion it is worthy of acceptance.

\begin{tabular}{c}
\hline Ronald Phillips, ArchD \\
\hline Gregory Bier, PhD \\
\hline Deanna L. Sharpe, PhD \\
\hline Newton D'Souza, PhD \\
\hline Ruth (Brent) Tofle, PhD
\end{tabular}


Thanks Dan for your unwavering support, encouragement and love. Through all of the events I missed, weekends that disappeared, late nights and re-writes, you have been so caring and understanding every step of the way, thank you from the bottom of my heart. I will always appreciate the friend, husband and father that you are.

Kenzie, thanks for being such a great sport over the years about sharing our family time with all the books, classes, computers and research. You were patient and kind, and for that, I will always be grateful. 


\section{ACKNOWLEDGEMENTS}

I would like to thank Dr. Phillips for his patience and guidance as I have worked through the research process. He provided many hours of consultation, instruction, and education with regard to the academic method and the work of environment-behavior professionals. Through his academic and experiential lens, and the instructional materials the coursework provided, I was able to see firsthand the impact of EB studies in all aspects of the human experience.

I would also like to extend my sincere gratitude to Dr. Tofle, Dr. Sharpe, Dr. D'Souza, and Dr. Bier for their willingness to be on my Committee and to provide support and review of this dissertation work. 


\section{TABLE OF CONTENTS}

ACKNOWLEDGEMENTS...............................................................

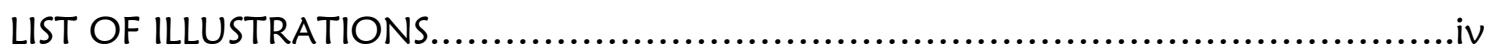

Chapter

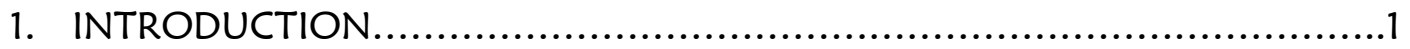

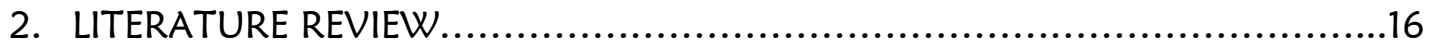

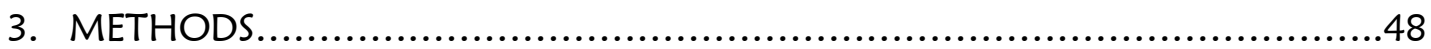

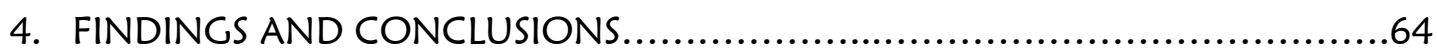

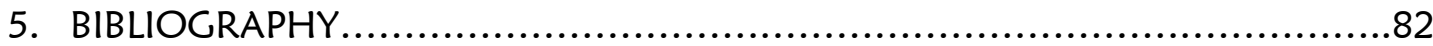

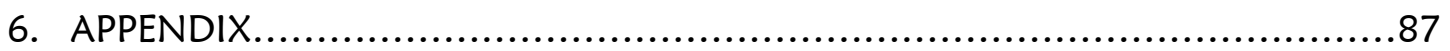

1. Letter of Informed Consent

2. Introduction

3. Workplace Attributes Survey

4. Analysis Plan

5. Additional Data

6. Vita 


\section{LIST OF ILLUSTRATIONS}

$\underline{\text { Table }}$

Page

1. 'Survey of Organizational Excellence' Dimension and Construct Items..........52

2. 'Seven Habits Benchmark' Dimension and Construct Items....................53

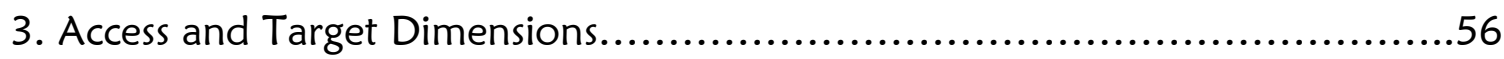

4. 'Place to Work' Dimensions and Constructs (SIRCA)..........................68

5. 'Place to Work' (SIRCA) Survey Items and Factor Loadings....................69

6. SIC Constructs and Mean Comparison (ACTUAL to IDEAL) ...................70

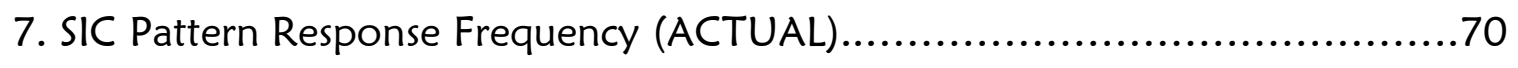

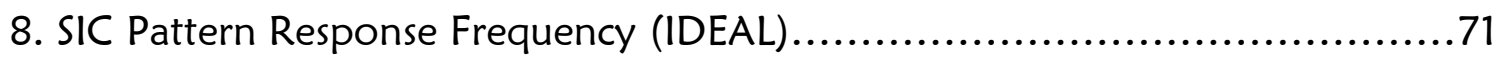

9. Organizational System Assessment Survey(OSAS) Dimensions and Constructs..72

10. OSAS Mean Pattern ALL RESPONSES - ACTUAL and IDEAL ....................73

11. OSAS and 'PWI' IDEAL to IDEAL Domain Pattern (ALL RESPONSES)...........74 


\section{Chapter One}

\section{INTRODUCTION}

The introduction of this research is organized in this chapter as follows:

(a) Background and Statement of the Problem

(b) Purpose of the Study

(c) Theoretical Framework

(d) Research Hypotheses

(e) Importance and Scope of the Study

(f) Definition of Terms

\section{Background and Statement of the Problem}

The modern workplace is significantly impacted by our shifting global economy, the influence of rapidly changing demographics and tight profit margins. Sustaining a business requires constant focus on resources and an eye toward ingenuity. An employer's inability to draw a bright line connection between workplace attributes and sustainability can create unhealthy and financially draining business cycles. Additionally, because many employers lack clarity regarding which qualities help sustain motivating work environments they are missing a golden opportunity to maximize production and profitability through aligned workplace attributes.

A fundamental lack of understanding of the employee's natural style of Environment Behavior (EB) preference from an organizational perspective limits an employer's ability to address fundamental business needs from a systemic perspective. This inability hampers the opportunity a company would have to match resources to need in a way that aligns with their current business model and 
employee desires. Misaligned allocation of resources and efforts eventually limit the return on investment for employers and employees alike.

\section{Purpose of the Study}

Numerous surveys are used in business settings to measure aspects of the workplace. In general, data are obtained to assist the employer in one of three general categories: 1) Culture and Leadership, 2) Products and Services and/or, 3) Competitiveness and Efficiencies. The application of survey data has been a powerful management tool providing useful information that can lead to key corporate decisions and strategic alignment of the workforce and services. Despite the availability of workplace survey instruments, to date no instrument exists to combine EB workplace attributes and preferences as it relates to the qualities that are present in highly successful, employee-centric workplace environments. Many employers are amenable to utilizing surveys to assess business operations and workforce perceptions if there is a tangible connection and direction from the data that speak to the company's fiscal bottom line. Logic would indicate that there is substantial goodwill that comes from creating a workplace and work environment that is great for the employees. However, in the grand scheme of maintaining a profitable business, employee-centered elements in the workplace are often associated with substantial costs and need to be vetted as good for overall business, or the capital investment may not be worth the return. This study incorporates the research of statistically related attributes of Fortune 500, Top 100 Best Places to Work companies through the application of the 'Place to Work' 
Index (PWI) and further evaluates the PWI attributes through the lens of

Organizational System preferences by employing the Organizational System Assessment Scale (OSAS). A combined tool was established to provide employers with an opportunity to match the work environment qualities and organizational system preferences of their workforce to the expenditure of monies used for work space, comp and benefit programs, training, professional development, cultural norms, etc.

\section{Theoretical Framework}

The work derives from a fundamental belief that an organization can be employee-centric, while maintaining strong profitability. There can be an ever present opportunity for win-win solutions and decisions for both employees and business. The key is to utilize research and analysis to provide a business case that motivates organizations to pursue this type of business model. Major theoretical considerations in this dissertation stem from the following areas: Organizational Behavior, Organizational Development, Organizational Systems, and Environment Behavior. It is the foundation of these behavior based sciences that provide a unique perspective for both the 'Place to Work' Index and the 'Organizational System Assessment'. These tools derive, in part, from commonalities of the human experience and speak to base human needs, wants and desires. The Index and its corresponding attributes: Security, Integrity, Reciprocity, Citizenship and Authenticity (SIRCA) provide a point of reference that businesses can manage to. For illustrative purposes, the individual constructs and dimensions of the 'Place to 
Work' Index and a high level overview of a few of the supporting components that are "in play" in organizations that illustrate a commitment to the SIRCA attributes are listed below.

Security: Ensuring the company's financial strength and the presence of security and stability in both the physical (office/workplace) and business environment (pay, policies, practices). The organization demonstrates integrity and commitment to its employees, the products and services, and customers through the manner in which they manage their financial strength and demonstrate financial flexibility. Diversification of assets, mitigation of risks, along with sound corporate governance, strategic planning and innovation provide the necessary risk/reward balance. Attention is paid to the physical work environment; efforts are made to offer physical space that promotes productivity, safety and security, while acknowledging individuality and endorsing both creativity and pragmatism. Pay, policies and business practices are deliberately designed and enacted to continually support and reinforce the company's mission, expectations and commonly held values.

Integrity: Behaving with integrity, building cooperative work systems by placing faith and trust in each other. The ownness for this tenet begins and ends with the executive team; the most important manifestation is leading by example. The message of integrity is conveyed through the manner in which business and strategic decisions are made, behavior is observed, and information is disseminated throughout the organization. Interdependence, cooperation and 
non-contentious partnerships are a mandatory component of both team and individual success. Employees are aware of the natural conflict, or "rub" that is inherent between operational business units; they understand differing roles and responsibilities naturally create opposing perspectives that are good for business when the interactions are managed to capitalize on both divergent perspectives and commonalities. Based on the organization's cultural norms and expectations "Rules of Engagement" are defined and managed to in meetings, projects and work. Emphasis is placed on providing opportunities for employees to know each other on a personal level and respect each other for the skills and talents they bring to the table; building camaraderie between people manifests itself as loyalty and support toward one another especially when work situations are difficult or needs/desires are in conflict with one another.

\section{Reciprocity: Valuing and nurturing the mutual benefit of a balanced} Employer/Employee relationship. Efforts are focused on the interdependency of the employer-to-employee relationship and the employee-to-business affiliation. Relationships are managed in a fair and complimentary manner; all parties are cognizant of the value of a stable workforce and of stable employment. There is a deliberate absence of the Big Me/Little You hierarchical management style. Expecting an honest day's work and effort for a competitive wage/benefit is key to the mutually beneficial union; entitlement mentality on either side is not tolerated. Company leaders make a concentrated effort to stay in touch with the work on the front line, to provide resources to continually develop talent, and to ensure that employees understand the breadth and depth of the responsibilities of 
leaders within the company. The employer and employees mutually share in the successes and failures of business decisions, progress toward goals, and in the achievement of milestones; there is an expectation that everyone will go the extra mile when the workload demands it, but the employer steadies the demands by ensuring that there are work/life balance opportunities and expectations in place. Decisions are made with the interests of both parties ever present.

Citizenship: Dedicated to doing the right thing in business dealings, in the work environment, and in the community. There is a fundamental expectation that business dealings are conducted in a manner that conveys both dignity and respect; that all employees treat those they come in contact with in a manner that demonstrates commitment to the company, colleagues, customers and the community. Every member of the organization strives to take care of their workday in an ethical and productive manner, to care for the communities they serve, and the people with whom they do business. The organization subscribes to do right by each other, to help those in need, and to look for win-win opportunities wherever possible.

Authenticity: Maximizing human interest, fortifying diverse environments where empathy, solidarity and tolerance is practiced, and individuality is acknowledged. The organization does not seek to create multiple reiterations of the same type of employee, but rather to capitalize on the benefits of miscellany. There is an understanding that tolerance of opposing viewpoints or personal traits is not an affront to one's own value system; people do not have to compromise their personal beliefs in order to co-exist in a professional and supportive 
environment with individuals who subscribe to a different ways of seeing the world and life experiences. The organization allows for personality to be present in the work space and in the workplace. There is a concentrated effort to incorporate human interest, fun and motivation into the work environment by encouraging employees to be genuine and true to oneself. The employer seeks to maximize individual strengths, provide opportunities for growth and development and minimize the emphasis on areas where the individual is not strong suited.

The other research tool that was employed as an integral part of this dissertation, the Organizational Systems Assessment Survey (OSAS), originated during the first part of the 1990's and stemmed from initial work in the family theory/family development field. The work of Kantor and Lehr (1975) identified the family as an organizational unit of analysis and began to build a theoretical framework around the unitization of the family structure. Imig and Phillips (1989, 1992) furthered the ability to statistically categorize and analyze the family unit through the development of the Family Regime Assessment Scale (FRAS), which identified family unit preferences and norms accordingly. In 1992 Phillips translated the theoretical premise of the FRAS into the environment-behavior (EB) domain to provide organizational application in the workplace through the development of the OSAS. The instrument, "assesses an organization's 'world view' or 'regime' across eight critical dimensions within two conceptual domains, identifies the dominant organizational regime, how its components interact, draws 
comparisons between 'actual' and 'ideal' conditions and links to the regime the environmental characteristics required to achieve an organization's desired goals. It meets the challenge of interconnectivity by embracing its intrinsic complexity rather than diluting it" (Phillips, 2012).

The OSAS has been in use for nearly 20 years and has resulted in environment behavior data collection from thousands of participants in cross industry work environments. Because the system approach of the OSAS work stems from an ecological perspective it has proven applicable in addressing the environmental factors associated with the organization-environment habitat. There are ten specific environment behavior attributes within the OSAS work: aesthetics, flexibility, accessibility, safety, comfort, privacy, quality, controllability, efficiency and collaboration. Phillips' work looks at the behavioral basis of design, focusing primarily on the Ecological Equation which is $B=P, E,(P \times E), B=$ Outcome Behaviors, $\mathrm{P}=$ Personal Characteristics, $\mathrm{E}=$ Environmental Characteristics, $\mathrm{P} \times \mathrm{E}=$ Interaction between Environment and Personal Characteristics. Deriving from extensive research that stems from Family Systems theories, Phillips has established four system preferences, also referred to as Organizational Regimes, that categorize the EB preference of individuals within a given work environment. The four systems, along with corresponding attributes, are listed below:

Closed: Continuity Oriented, Stability, The Organization Comes First, Loyalty, Minimize Change, Hierarchical Structure, Diverse Viewpoints Not Permitted, Traditional. "We do things this way because that's the way we've always done them." 
Random: (Opposite of the Closed System) Discontinuity Oriented, Individuality Focused, Self-Interest Comes First, Absolute Minimum Organziation, Promotes Change, Heirarchical Structure is Avoided, All Viewpoints Encouraged, Creativity. "Do your own thing."

Open: (Integration of Closed and Random Systems) Concensus Oriented, Adaptability, Individual and Organizational Interests are Equal, Dialogue, Discussion and Negotiation are Sought After, Interdependence, Seek Information Useful for Problem Solving, Cohesive. "We can talk it out."

Synchronous: Peace, Harmony and Tranquility, Cooperation Without Conflict, Commitment to Perfection, Individual Interests and Organizational Interests Coincide, Understructured, Smoothly and Closely Coordinated, Interdependence, Organizational Identity and Membership is Paramount, Timelessness. "What is, is; what is not, is not."

Administering the 'Place to Work' Index (PWI) in conjunction with the Organizational System Assessment Scale (OSAS) in a combined survey tool provides a new landscape for the examination and analysis of Environment Behavior attributes in the workplace. The Index and Scale were blended and modified to create a Workplace Assessment Survey entitled Organizational 
Learning Survey: University of Missouri Extension. Using the Multi-Attribute Utility Technology (MAUT), the research links work environment preference (OSAS) to the SIRCA attributes of the Place to Work Index (PWI), by order of importance and by order of what is actually occurring in their current work environment. This ordering provided a ranking of priorities for the organization to be used as a potential roadmap for planning and execution of employee-centric components that matter most to their present workforce.

\section{Research Hypotheses}

It is proposed that a relationship between the 'Place to Work' Index and the Organizational System preference scale exists. If this relationship is found, the null hypothesis of Organizational Style preferences as random and unrelated to specific Index attributes will be rejected. By further understanding the relationship between level of importance with regard to 'Place to Work' Index attributes and the interplay said attributes have with Organizational System preferences employers will be provided with a straightforward mechanism to better understand their workforce, the current work environment and how to manage to the Index attributes.

To illustrate this concept consider that Authenticity is one of the core factors of the PWI, the research study findings may indicate that employees who rank $\mathrm{HICH}$ on Authenticity also rank $\mathrm{HICH}$ on the OSAS preference for Random. If this illustration proves statistically valid there are environment behavior 
preferences that could manifest as decision points for the employer. A simple example for Random/Authentic would be the ability for individuals to personalize their workspace, or a business casual dress code that allows for a more relaxed environment and individual expression. From a benefits perspective, an emphasis on choice would be important (i.e. Offering Health Savings Accounts (HSA's), PPO's, High Deductible Health Plans). Providing business with an opportunity to have a basic breakdown of their workforce from this evolutionary perspective creates an opportunity for employers to invest money and resources into the EB items that are important to their employees. By investing wisely, the return (ROI) is a work environment that has the attributes in place that its employees desire, thereby contributing to the employer's ability to attract and retain a highly productive workforce.

\section{Importance and Scope of the Study}

This dissertation is designed to contribute to the body of knowledge on two fronts: 1) to further encourage the pursuit of research and academic interest in workplace studies from an Environment and Behavior (EB) perspective, and 2) to provide an application guide for practitioners, businesses and researchers to use if they are interested in pursuing and sustaining work environments that have the qualities of profitable, employee-centric organizations.

The contributions are critical to the field at this time for three main reasons. First, Environment and Behavior studies has an opportunity on the horizon to 
expand beyond was has traditionally been seen as a science that is tied heavily to the built environment and the interaction within it. The domain is primed to expand into an increasingly holistic environmental approach wherein all aspects of the human experience can be pulled into the research and the science. The design, the build, the work, the processes, the environmental "norms", the psycho-social, and socio-economic indicators all play at once an increasingly complex and integrated role in the ongoing evolution of Environment and Behavior studies. This dissertation work contributes to the effort to expand on the base principles of $E B$ and continue to formulate new application.

Second, as discussed previously, there are numerous surveys that are used in business settings to measure aspects of the workplace. The data are obtained in order to assist the employer in one of three general categories: 1) Culture and Leadership, 2) Products and Services and/or, 3) Competitiveness and Efficiencies. This dissertation will provide an Environment Behavior tool for application in the workplace where currently, no Index exists. The tool can assist businesses in creating economies of scale by offering a blended approach to the three traditional data categories, in conjunction with the EB attributes. Efforts will focus on the compliment and/or contrast respective workplace environments have in relationship to the thematic qualities of financially successful, employee-centric workplaces. The information derived from this study will assist business leaders in their decision making process as they look to create a more befitting, deliberate work environment for their employees. 
The third component of this dissertation's contribution is the opportunity to provide an Index that can be used for further research in the workplace. The 'Place to Work' Index, can be combined with other assessment tools to measure the relational perspective of multiple measurements. It can also be applied to various demographic components. For instance, a researcher who is interested in gender preferences in the workplace could apply the Index through the lens of gender and establish whether or not there is a gender bias preference on the Index qualities. The tool can also be used by the academic community to combine with other multi-disciplinary research methods to further pursue the theoretical links between the worker and work place.

\section{Definition of Terms}

This dissertation utilizes both unique and common terms, acronyms and definitions. The following definitions are provided to ensure uniformity and understanding of these terms throughout the study. All definitions not accompanied by a citation were developed by the researcher.

Employee-Centric Companies: Workplaces that focus on investing in, and providing for, a work environment that supports the employee in a holistic manner through comprehensive workplace programs that meet the employee's needs and desires for meaningful work, individuality, autonomy, support and recognition.

Environment and Behavior (EB): The study of the mutual relations between human beings and the physical environment at all scales and application of this 
knowledge thus gained to improving the quality of life through better environmental policy, planning, design and education (Moore, p12, 1985).

Fortune 500: An annual listing published by Fortune magazine that lists the top 500 U.S. privately held and public corporations as ranked by their gross revenue after adjustments made by Fortune to exclude the impact of excise taxes. Although there are other financial listings used in the business industry, the Fortune 500 listing has endured since 1955, in part because of the unbiased revenue based criteria, which is considered to be less volatile than other competitor indexes (www.investinganswers.com, 2013).

Great Place To Work Companies: Fortune magazine's Top 100 Places to Work. Companies that are at least seven years old with more than 1,000 U.S. employees were eligible to participate. An extensive survey and culture audit was used to select the top 100 employers. The survey included items related to employee attitudes about management's credibility, job satisfaction and camaraderie. The culture audit included questions related to pay and benefit programs and open-ended questions about hiring practices, diversity efforts, internal communication, training programs and recognition programs (www.greatplacetowork.com, 2013).

Organizational Assessment Survey (OSAS): An instrument used to assess an organization's 'world view' or 'regime' across eight critical dimensions within two conceptual domains (Phillips, 2012).

Organizational Behavior (OB): The study of individuals and their behavior within the context of the organization in a workplace setting. It is an 
interdisciplinary field that includes sociology, psychology, communication, and management" (Cornell University School of Industrial and Labor Relations, 2011).

Organizational Development (OD): The systematic application of knowledge of behavioral science at different levels, such as group, inter-group, organization, etc., to bring about planned change with the objective being enhanced quality of work-life, adaptability, productivity and effectiveness (Newstrom \& Davis 2007).

Organizational Learning Survey: The University of Missouri Extension: The survey used in this dissertation to combine the attributes of the 'Place To Work' Index and the Organizational Systems Assessment Survey.

Organizational Systems Thinking (OS): The study of organizations through the mechanics of interaction. It views systems as a collection of parts or sub systems that integrate, either naturally or by design, to accomplish a common goal (Phillips, 2012).

'Place to Work' Index (PWI): An Index that describes the five statistically related attributes of the 'Place to Work' Survey.

SIRCA: An acronym for the attributes (Security, Integrity, Reciprocity, Citizenship, Authenticity) associated with the 'Place to Work' Index. 


\section{Chapter Two}

\section{LITERATURE REVIEW}

The review of literature in this chapter is intended to provide a historical overview of some of the major theoretical building blocks and evolution of the following social sciences:
(a)Organizational Behavior
(b)Organizational Development
(c) Organizational Systems
(d) Environment and Behavior

"Each one of us is like that butterfly in the Butterfly Effect. And each tiny move toward a more positive mindset can send ripples of positivity through our organization, our families and our communities."

(Achor, 2011)

\section{Historical Background}

Each move, action and reaction in one's respective work environment has the potential to send behavioral ripples into the workplace, the families with whom one lives and out to one's community. Organizational research into this systems theory supposition demonstrates a far-reaching sociological impact. This ripple effect, when manifested in a positive way, commonly referred to as the manifestation of positive psychology, can move through the organisms, large and small, with an infusion of happiness and social goodwill. This behavioral pattern, in the work setting, creates an environment in which highly productive workplace functioning can thrive (Achor, 2011). Positive psychology first found its social 
science designation in the early 1990's. Since that time, the research has made a profound impact on the study of human behavior and motivation in the workplace. To understand the impact of workplace social sciences, the combined attributes of Environment and Behavior, Organizational Behavior, Organizational Design, and Organizational Systems should be traced. The future potential of the work environment is built in part on the evolution of modern workplace management. Understanding some of the historical indicators of this evolution proves useful in building a theoretical foundation for this dissertation.

The work of Peter Drucker, a man who has been commonly referred to as the "Father of Modern Management" (Wartzman, 2011), has placed a significantly influential footprint on the work of organizational management, human motivation and behavior. As a researcher, professor, management consultant and self proclaimed "social-ecologist", his writings contain instruction about how workers can find a sense of community and dignity in a society that is organized around modern (work related) institutions, and how if managed in a dignified and humane way, organizations can bring out the best in people (Wartzman, 2011). Drucker wrote that management at its core, "Deals with people, their values, their growth and development, and this makes it a humanity. So does its concern with, and impact on, social structure and the community. Indeed, as everyone has learned who....has been working with managers of all kinds of institutions for long years, management is deeply involved in moral concerns--the nature of man, good, and evil" (Wartzman, p4, 2012). His work paved the way for societal recognition that, "Managing oneself is a revolution in human affairs. The shift 
from manual workers who do as they are being told, either by the task or by the Boss - to knowledge workers who have to manage themselves profoundly, challenges the social structure" (Drucker Institute, 2011). The Drucker perspective further generated the growth of interdisciplinary workplace research that has become a vital part of the knowledge and direction on which modern businesses rely.

The success of any organization is in large part accomplished through the ability of resources to come together for a common cause and to be motivated to continue progressing in a unified direction. Because business success and commerce is at the core of all thriving societies, it is a much discussed and researched global topic. From the products that people buy, the psychology and motivation of the worker, the qualities of successful leaders, the space and pace of the business, and organizational dynamics, scholars and business alike seek to understand the sustaining ingredients of successful ventures. In particular, the study of Organizational Behavior (OB), Organizational Development (OD), Organizational Systems (OS) and Environment and Behavior (EB) have become critical to the evolution of understanding business, work and the worker.

Andrew Ore (1835) planted some of the first OB, OD, OS and EB seeds through his effort to incorporate and write about the human factor within the work environment. In his book, The Philosophy of Manufactures, he wrote about the commonly accepted mechanical and commercial parts of manufacturing, but he also thrust the initial concept of social science forward by incorporating a third component, human behavior. Initially, Ore's contemporaries refused to embrace 
the concept, but eventually the human component began to develop into the strands of what would become modern organizational studies.

\section{Organizational Behavior}

Organizational Behavior (OB) is defined as, "The actions and attitudes of individuals and groups toward one another and toward the organization as a whole, and its effect on the organization's functioning and performance" (BusinessDictionary.com, 2011). From an academic perspective, it has been defined as, "The study of individuals and their behavior within the context of the organization in a workplace setting. It is an interdisciplinary field that includes sociology, psychology, communication, and management" (Cornell University School of Industrial and Labor Relations, 2011). Both definitions point to the intertwining relationships of people and behavior in the work environment. The objective of $O B$ is to investigate and apply information about how individuals and groups behave in organizations. It is understood that the modern workplace is in constant flux. It is evolving and changing depending on an array of variables within the organization (i.e. technology, products, people) and in the external environment (i.e. legislation, economics, consumer demographics). The goal of Organizational Behavior research is to help explain, predict, and shape aspects of the organizational environment. The foundation of $O B$ is based on the vision, values, mission and philosophy of an organization's leaders. This foundation manifests itself as the culture within the organization. Within business, the manifestation of $\mathrm{OB}$ can be both formal (i.e. policies, procedures) and informal (i.e. social environment, decision making). It drives environmental components, 
also referred to as "norms", like the selection of leaders, the preferred style of communication and engagement, and the dynamics of working groups to name a few. These workplace norms directly impact the individual employee's perceived work life quality and their corresponding level of motivation and desire (Covey, 2006). It is the amount, or level of, motivational experiences in which the individual engages that propels his/her personal level of performance, job satisfaction and development. Deriving from the experience of many individuals, there is a collective norm that forms and in turn either destabilizes or reinforces the overall organizational foundation. This is the process by which the organization continues to evolve and operate.

Douglas McGregor (1957) developed Theory $X$ and Theory $Y$ to explain two opposing approaches to viewing human behavior within the workplace and organizations. He theorized that organizations and their corresponding managers followed one of the two approaches. Theory $X$ contends that management's role is to coerce and control employees because individuals 1 ) have an inherent dislike for work and will avoid it if at all possible, 2) must be coerced, controlled, directed, or threatened with punishment in order to get them to follow business objectives, 3) prefer to be directed, have little or no ambition and withdraw from personal responsibility, 4) seek security above all else. Theory $Y$ contends that management's role is to lead, motivate and inspire. Under this theory individuals 1) view work as an integral part of being human, just like play and rest, 2) have potential, 3) exercise self-direction if they are committed to the objectives, 4) seek responsibility and learn to accept change and flux, 5) are capable of using 
creativity, ingenuity and imagination to solve organizational problems and dilemmas, and 6) experience a strong sense of personal reward when they achieve. It is in part from McGregor's Theories that four primary models of Organizational Behavior evolved.

Within the $\mathrm{OB}$ discipline there are four commonly recognized models (Autocratic, Custodial, Supportive and Collegial) that encompass the behavior tendencies of an organization. These models are not individually exclusive within the work setting, but rather, organizations predominantly align with one model as primary with secondary traits stemming from the remaining models. A brief description of the characteristics of the four models is described as follows (Heill, Bennis \& Stephens, 2000).

Autocratic Model - Authority is positioned exclusively with management. Employees act out of obedience and dependence. Performance results are baseline minimal and the employee is rewarded through continued subsistence. This model stemmed from the industrial revolution and is associated with Theory $X$.

Custodial Model - Authority is positioned with management. Primary management motivation is money. Employees are oriented toward financial security and benefits. Performance results are baseline passive cooperation and the employee is rewarded through security. This model is associated with Theory Y.

Supportive Model - Authority is positioned with management, but it is oriented toward supportive leadership. Employees act in a participatory manner and are motivated to perform. Performance results are met through individual 
motivation and the employee is rewarded through recognition and appreciation. This model is associated with Theory $\mathrm{Y}$.

Collegial Model - Authority is positioned as a partnership and is oriented toward teamwork. Employees act in a manner that is based on personal responsibility, self-motivation and self-discipline. Performance results are met through relationship interdependence and enthusiasm. The employee is rewarded through self-actualization. This model is also associated with Theory $Y$ and is thought to be the model with the most evolutionary potential as business and societal expectations continue to change.

In complement to McGregor's Theory Y, but in sharp contrast to other psychological research of his time, Abraham Maslow's theoretical work on human needs focused on the idea that when needs were met people were inherently driven toward creativity and would enlist all of their talents and capabilities to meet their full potential (Bootzin, Loftus, Zajonc \& Hill, 1983). He developed a Hierarchy of Needs wherein the drivers of human behavior were categorized into two areas: basic human needs and higher order needs (called meta-needs). Basic needs encompass the physiological and psychological dimensions of the human experience, meaning the physical survival items such as food, water, sleep and sex, and emotional survival items like security, self-esteem and affection. These physical and emotional items make up the level of basic needs. Maslow (1970) referred to meta-needs as a human's growth needs that included more esoteric items like beauty, order, unity, goodness and a state of wellbeing. 
According to the Hierarchy, basic needs take priority over meta-needs. To illustrate the ordering of human needs, Maslow slotted them in the form of a pyramid, starting with the most basic instinctual human need, the Physiological, followed upward by Safety, then Belongingness and Love, Esteem and finally transcending to Self-Actualization. In the later years of his career, Maslow focused primarily on the meta-needs in an effort to further delineate the higher order. He posited that the ultimate goal of one's life is to reach Self-Actualization, and although according to Maslow it is never entirely achieved, the sheer action of striving toward the goal provides a greatly enriched human experience. As Maslow finalized his pyramid of needs, he moved beyond Self-Actualization into what he considered the ultimate peak of the needs pyramid, Self-Transcendence. This need component transports the individual to the level of spiritual existence (Maslow Summary, 2011).

Maslow's work has been criticized for over-generalizing human needs and individual evolution patterns. His work, however, is considered a major building block from which the studies of $\mathrm{OB}, \mathrm{OD}, \mathrm{OS}$ and $\mathrm{EB}$ have been influenced. Perhaps Maslow's most influential premise is that humans inherently strive to meet goals. Accordingly, if base needs or goals are met the individual is freed up, so to speak, to have the mental and emotional capacity to strive for higher level developmental goals. This work paved the way for advanced thought on human motivation. As it was applied to the work environment, it provided an opportunity to make the connection that those who have their basic needs met have the physical and psychological ability to become better workers; they have 
the capacity to focus on more goal oriented work and stretch opportunities, developing their own potential, rather than constantly struggling with existence and subsistence issues.

\section{Development of Motivational Theories}

Building on the tenets of Maslow's Hierarchy of Needs, Frederick Herzberg (1966) was regaled as one of the most influential subject matter experts of his time with regard to the working environment. His body of research is most notably recognized through his focus on hygiene and motivation. What Herzberg termed Hygiene Factors were considered potential 'dissatisfiers' in the workplace. Herzberg posited if the hygiene factors (basic work related needs) are not met then the employee is unable to respond to higher-level workplace motivators. The Hygiene Factors are: 1) Working Conditions, 2) Policies and Administrative Practices, 3) Salary and Benefits, 4) Supervision, 5) Status, 6) Job Security, 7) CoWorkers and 8) Personal Life. If these factors are met, an employee can be motivated by new and somewhat evolutionary opportunities. These motivating factors are: 1) Recognition, 2) Achievement, 3) Advancement, 4) Growth, 5) Responsibility and 6) Job Challenge. Helzberg created the term "job enrichment", which is described as the process of redesigning work in order to build in motivators by increasing both the number of tasks that an individual performs and the control that he/she has over the specific tasks (autonomy).

Clayton Alderfer also built upon Maslow's foundation creating a theoretical position that he coined the Existence/Relationships/Growth (ERG) Theory of Needs (1969). He postulates that three core human needs exist. Physical and safety 
requirements called Existence needs encompass basic provisions needed for material existence. These needs are satisfied through the use of money, which most people obtain in exchange for providing work related services. The second component, Relationships, centers on the innate desire to seek out and maintain personal relationships. Individuals normally spend a large portion of their adult life in a work setting, which naturally leads to the pursuit of at least partial satisfaction of this core need within the workplace with co-workers and colleagues. The final core area, according to Alderfer is Growth. This need is met through individual development. Again, because of the significant amount of time that most adults spend in the work environment, individual's job, profession, or career, is a key source for providing the opportunity to meet this core need. In contrast to Maslow's Hierarchical Needs Theory, Alderfer's Theory posits that more than one need at a time may be influencing an individual, causing the core needs to exist more on a continuum rather than a hierarchy.

Although Maslow and Alderfer disagree over their application of human need, they share the same theoretical perspective that individuals will tend to work to achieve basic and safety needs first and foremost before they experience motivation to work toward meeting other needs. A recent study (Tay \& Diener, 2011) also confirmed that individuals seek to satisfy basic needs before moving toward addressing subsequent evolutionary needs. The researchers further identified that the act of satisfying the various needs provides an almost independent effect on the individual's "subjective well being"(both biological and emotional). The researchers argued that the act of need satisfaction is arranged 
more like a box. Instead of the previous theories like Maslow's pyramid or Alderder's continuum, Tay and Diener describe basic human needs as scattered within the box and depending on the environment or the situation that is presented, different needs push to the top to compensate for areas where other needs have become deficient.

As research in the sciences continued to evolve it became clear that within the emerging disciplines of $\mathrm{OB}, \mathrm{OD}, \mathrm{OS}$ and $\mathrm{EB}$, individual motivation was being presented as a driving force for all behavior traits. Motivational theories that also emerged in addition to Herzberg's began to populate the social and psychological sciences. Although there are numerous motivational theories to date, the majority can be categorized into three general theories. They are: 1) Content Theories that energize behavior, 2) Process Theories that direct behavior and 3) Behavioral Theories that sustain behavior. The three categories are not seen as competing explanations of the same construct, but rather each is operating as part of a continuum, much like the continuum process described by Alderfer. Energizing Behavior Theories seek to understand what initiates the behavior, behavior pattern, or changes to one's behavior. Directing Behavior Theories seek to explain what factors determine which behavior an individual selects. The focus is on the question of choice and conflict within competing behavioral options. Sustaining Behavior Theories seek to quantify what factors determine an individual's level of persistence with respect to behavioral patterns and to understand how behavior is sustained or ended. All areas have direct interest from, and relevance to, the work 
environment. Today, it is commonly recognized that understanding employee motivation is a key to unlocking human potential and workplace productivity.

In modern application, businesses and academia have foundational research that stems from three well known theories of human motivation: 1) Vroom's Expectancy Theory, 2) Adam's Equity Theory and 3) Locke's Goal Setting Theory. Although all three theories have experienced sustaining application, their theoretical work is not always in compliment of one another. Vroom's work through the Yale School of Management emerged as early research on human behavior and motivation that had application in the development of $\mathrm{OB}, \mathrm{OD}, \mathrm{OS}$ and EB. Vroom defines motivation as a process governing choices among alternative forms of voluntary activities, a process controlled by the individual. The individual makes choices based on estimates of how well the expected results of a given behavior are going to match up with, or eventually lead to the desired results (Vroom, 1964).

From Vroom's perspective, people will be motivated to act in a specific way based on the belief that once they perform the action it will be subsequently followed by a given outcome. Their motivation to perform the act is in large part based on how attractive the expected outcome is to the individual. Vroom listed his theory as a formula: Valence $\mathrm{x}$ Expectancy $\mathrm{x}$ Instrumentality $=$ Motivation. The model has been updated, most notably by Porter and Lawler (1968) to reflect a more refined approach. The formula was further delineated into Motivational Force $(\mathrm{MF})=$ Expectancy $($ Expectancy to Probability) $\times$ Instrumentality (Probability to Reward) $\times$ Valance (Reward) or $(\mathrm{MF}=\mathrm{E}, \mathrm{P} \times \mathrm{P}, \mathrm{R} \times \mathrm{V}(\mathrm{R}))$. Expectancy is a 
personal conclusion that one's effort will result in the attainment of desired goals. Instrumentality is the understanding that if one meets the performance expectations, the individual will receive a greater reward (i.e. job promotion, merit increase, sense of accomplishment). Valence stems from the actual value the individual places on the identified reward. All three components work in tandem to help define what behavioral options are available to the individual. Under this theory, the individual will pursue the option that possesses the strongest Motivational Force.

Behavioral and workplace psychologist John Stacey Adams developed a job motivation theory in 1963 called Adams Equity Theory. His work posits that a fair balance needs to be present between the work efforts of the employee (called “inputs") and the employer efforts (called “outputs"). Inputs include intangible items like: Effort, Loyalty, Hard Work, Commitment, Skill, Ability, Adaptability, Flexibility, Tolerance, Determination, Enthusiasm, Trust in Superiors, Support of Colleagues and Personal Sacrifice. Employer outputs include tangible items like Salary, Benefits and Perks. Intangible employer items include Recognition, Praise, Responsibility, Reputation, Stimulus, Sense of Advancement and Job Security. Adam's Theory explains that where there is perceived balance between employee inputs and employer ouputs, an optimal environment is created. This environmental opportunity provides for a strong and productive relationship between both employer and employee, and a place in which content and motivated employees exist and thrive (Spector, 2008). 
Edwin Locke pioneered research in the late 1960's on goal setting and human motivation. His writing, "Toward a Theory of Task Motivation and Incentives" (1968) created a new paradigm from which to observe and evaluate employee motivation. Locke's research demonstrated that employees were motivated by clear goals and appropriate feedback, and that having the ability to work toward a specific goal, gave the employee a significant source of motivation to push toward goal attainment and resulted in improved performance on the job. Gary Latham, a Professor of Organizational Effectiveness at the University of Toronto, also joined Locke in the study of motivation and goal setting. Their work together found that specific, difficult goal setting, directly leads to significant increases in employee productivity (Locke \& Latham, 1984). In 1990 the two researchers published "A Theory of Goal Setting and Task Performance" in which they reinforced the need to set specific and difficult goals. They also set forth five principles of effective goal setting: 1) Clarity, 2) Challenge, 3) Commitment, 4) Feedback and 5) Task Complexity.

\section{Organizational Development}

Organizational Behavior (OB) and Organizational Development (OD) are similar in that their applied science is to understand and influence the dynamics and behavior of individuals and their corresponding environments. However, each takes a somewhat different approach to how they view and value the different influencers within a given environment. $O D$ is defined as the "theory and practice of planned, systematic change in the attitudes, beliefs and values of the employees through creation and reinforcement of long-term training programs. 
OD is action oriented. It starts with a careful organization-wide analysis of the current situation and of the future requirements, and employs techniques of behavioral sciences such as behavior modeling, sensitivity training and transactional analysis. Its objective is to enable the organization to improve adaption to the fast-changing external environment of new markets, regulations, and technologies"(BusinessDictionary.com, 2011). It has also been described as the systematic application of knowledge of behavioral science at different levels, such as group, inter-group, organization, etc., to bring about planned change with the objective being enhanced quality of work-life, adaptability, productivity and effectiveness (Newstrom \& Davis 2007). Bradford and Burke (2005) explain that the way in which the quality of the environment and corresponding work is altered and enhanced is through the act of influencing and changing behaviors, attitudes, values, strategies, procedures and structures in order to maintain an organization that is adaptable and pliable enough to keep pace with the demands for change in any given work environment.

Kurt Lewin developed four elements that became part of the impetus work of Organizational Development. Field Theory, Group Dynamics, the 3-Step Process for Successful Change and an influential process coined "Action Research" became early building blocks for OD. Although it has been disputed as to whether it was actually Lewin or one of his research partners, John Collier, who invented Action Research (Cooke, 1999), what is clearly known is that the steps to actionoriented change presented a unique opportunity for new research possibilities in the budding social science. Lewin described Action Research as a method of 
comparative research that incorporated the conditions and effects of all types of social action and research. The process was considered to be a "spiral of steps", with each part of the process consisting of planning, action and fact-finding about the outcome, or results of the action (Lewin, 1946).

In part because of Lewin's work and as a result of quickly evolving post World War II cultural, business and societal changes, OD emerged from multiple disciplines. Cummings and Huse (1989) point to four major activities that propelled OD into existence, three of which Lewin either originated or greatly influenced before his death in 1947. They are: 1) Action Research, 2) Survey Research Feedback, 3) Laboratory Training, and 4) Quality-of-Work-Life (QWL). John Collier, Kurt Lewin and William White found that organizational research needed to be linked closely to a quantifiable action if members of a given organization were going to use the research to manage and effect change (Marrow, Bowers \& Seashore, 1970). Survey Research Feedback came from the work of the Research Center for Group Dynamics that Lewin formed at MIT in 1945. The Center was later moved to the University of Michigan to join the Survey Research Institute as part of the Institute for Social Research. The work of the Center while at Michigan also influenced the emerging development of Environment and Behavior Research. The National Training Laboratories (NTL) worked with the Research Center for Group Dynamics to develop training groups called sensitivity groups or T-groups. Lewin had been asked by the Connect Interracial Commission and the Committee on Community Interrelations of the Jewish American Congress to assist in training of community leaders. Lewin's 
group observed the behaviors of individuals and group dynamics and then discussed the behaviors with fellow researchers at the end of the day. The community leaders requested that they be allowed to be present at the feedback sessions.

This new dynamic provided an opportunity for individuals to hear and react to information about their own behavior, from the vantage point of others, creating the glide path for OD work. Quality-of-Work-Life (QWL) research came to the United States from Europe in the 1950's and was based in large part on the work of Eric Trist from the Tavistock Institute on Human Relations in London. The work examined both the technical and human aspects of organizations and work environments and how the two areas are interrelated and interdependent (Cummings \& Huse, 1989).

Lewin's work has often been criticized primarily because of his assumption that organizations operated in a stable state. This premise could not be widely applied to large scale change projects, it was considered a top down change management approach that eventually lost its mainstream appeal, and his "stable state" approach did not acknowledge the presence or influence of organizational power and politics (Burnes, 2004). His work did, however, create a far-reaching research foundation on which others could build. He was, "a humanitarian who believed that only by resolving social conflict, whether it be religious, racial, marital or industrial, could the human condition be improved, Lewin believed that the key to resolving social conflict was to facilitate learning and so enable individuals to understand and restructure their perceptions of the world around 
them" (Burnes, p981, 2004). This approach created opportunity for many advances in the OD world.

John French, a noted OD researcher, also listed the work of a human relations group at the ESSO Company as a catalyst for OD evolution. Rather than working as a traditional Research and Report Writing Unit, the human relations group at ESSO created an internal consulting unit to offer systematic review and assistance to field managers. Additionally, the rapid technological developments of the 1960's and 1970's further accelerated the need for OD. Project groups, task forces and change management processes required new and innovative approaches to managing business requirements and emerging technologies (French, 1982).

Notable researchers, like Peter Vaill and Craig Lundberg, have continued efforts to further develop OD as a practical science. Vaill has been cited as, "One of the Country's top 10 organizational development specialists; Vaill is known for his ideas on what he's termed 'permanent white water', the turbulent social and organizational conditions that managerial leaders face today" (Harvard Business School, 1999). Lundberg has introduced a theoretical perspective termed Social Rules Theory to assist in reframing and redefining organizational change and development. It may be redefining OD as a special type of: "Project system in organizations which facilitates change by surfacing, assessing and modifying as needed, the rules and rule systems within or linking organizational components" (Lundberg, 2000). Their work, although targeted to the OD specialty, continues to be influential in the evolution of $\mathrm{OB}, \mathrm{OS}$ and $\mathrm{EB}$ practices. 


\section{Organizational Systems}

The nature of Systems Thinking (OS) is an application approach for OB, OD and EB work. It looks at a system as a collection of parts or sub-systems that integrate, either naturally or by design, to accomplish a common goal. The system itself moves through varied processes. It has inputs, outputs and outcomes that derive from all areas of the system. If there is a change to any part of the sub system, the overall is system is forever altered. A system can come in almost any form, from ecological (food chain), to biological (circulatory system), to mechanical (computers), to social (work groups). The crux of approaching systems thinking is to focus on the complexity, diversity, dependence and interrelatedness of all organisms. Systems thinking applied to organizations (OS) creates opportunity for environment management at all levels of an organism or organization.

One of the originating methods used to investigate systems thinking from the sociological human perspective has been work that is based on what is known as the Family Paradigm Theory (Kantor \& Lehr 1975). This Theory supplies a structure that can be conceptually applied to the how and why of human movement through day-to-day activities. Because the work is firmly rooted in family dynamics, it has offered a useful application for organizing and understanding the diverse nature of human interaction, observable behavior and cultural norms. The systems concepts of family or group dynamics lends itself to application in the work environment. By further understanding the patterns and 
worldviews that emerge from and within the human systems setting, the relationship between the system and its environmental attributes can be further understood. This deeper understanding supports proactive activities in the workplace that focus on creating structures or opportunities that incite behaviors to drive and determine events, rather than just operating in a reactionary mode.

\section{Environment-Behavior}

The third connector point in the triangle of human behavior and environment study is Environment-Behavior (EB) research. Again, EB research is similar to $\mathrm{OB}, \mathrm{OS}$ and $\mathrm{OD}$ in the applied sciences, but different in its approach to viewing and valuing the different influencers within a given environment. When seeking to understand the Environment-Behavior (EB) connection and how EB study is becoming paramount in the modern workplace, it is also helpful to understand its origins, distinctions, and underlying influence. EB research focuses on the, "study of the mutual relations between human beings and the physical environment at all scales and application of this knowledge thus gained to improving the quality of life through better environmental policy, planning, design and education" (Moore, p12, 1985). In its most basic form, behavior is seen as the way in which a person, organism, or group responds to a specific set of conditions or their environment. In turn, the term environment references a specific set of external conditions and often acts as a stimulus for the way people experience their environment and subsequently react and behave within and toward it. The relationship between the two can present as both straightforward 
and entirely complex, making the EB study and research well suited for multiple disciplinary approaches serving as an evolutionary tool for workplace development.

From human's earliest origins, people have demonstrated, "a distinctive pattern of adaptations that reflected the requirements of the particular environment from which they emerged" (Kaplan, 1972). Humans worked to facilitate a way of meeting their needs and moving their way of life toward a more soothing and comfortable condition. Their purposive behaviors were, and remain, stimulated by needs that require fulfillment. This pursuit is an intrinsic and nurturing property of the human experience, and therefore common to all behavioral traits. Behavior, as a trait, is an overt action that is not only controlled by needs but also by various subsystems such as physiological, social, cultural and personality dimensions of the human experience (Porteous, 1977).

When examining the environment-behavior interaction, it is evident that $E B$ is one of the most reliable touch points of man's relationship to self, to each other, and to one's universe. Simply stated, "The history of life on earth has been a history of interaction between living things and their surroundings" (Carson, p4, 1962). As a result, human response, anticipation and planning (as it relates to the environment) have altered both physical life and the environment, and have changed reality accordingly. Environmental Psychologist, Robert Bechtel refers to this concept as the "Rich Response Repertoire" (RRR), which involves developing many different responses or reactions to a single situation. He states that, "The 
richness to responses is the key to evolutionary success, and collecting them into a repertoire provides the kit for survival" (Bechtel, p49, 1997).

It is conceivable that RRR may also be seen as the impetus for two areas of workplace study and research: Emotional Intelligence (EI) and Cultural Intelligence (Cl). Emotional intelligence focuses on the criticality of dealing effectively with human emotions in varied settings. It recognizes that human brains are hard-wired to give way to base emotional responses. Everything that is seen, smelled, heard, touched or tasted comes into the body through the primary senses and travels through the biological pathways in the form of electro-chemical signals. Before the signals can move through and into the frontal lobe of the brain where rational thought prevails, these impulses must migrate up the spinal cord and through the limbic system within the brain where core emotions are experienced by the individual. As a result, there is a constant biological and mental struggle to manage or succumb to the fierce interplay between felt emotions and rationale reaction. Emotional Intelligence was a term coined to help explain this human sensitivity, or lack thereof, in observed and demonstrated behavior within environmental settings. Highly successful El traits include displaying substantive levels of sophistication, discipline and forethought in an individual's management of the internal relationship between the brain's emotional and rationale processes and outwardly demonstrative behavior. The more confirmed control one has over his/her emotional response, the higher the observed level of emotional intelligence and, consequently, one's level of predictable success in relationships and in the workplace (Earley, 2004). Cultural Intelligence is related to Emotional 
Intelligence, but it picks up where Emotional Intelligence leaves off. A person with high El grasps the nuances of what makes us human and at the same time, what makes each of us different from one another. A person with high Cultural Intelligence takes it a step further and can somehow tease out of a person's or group's behavior those features that would be true of all people and all groups, those peculiar to this person or this group, and those that are neither universal nor idiosyncratic" (Bradberry, p1, 2004).

Both perspectives are applicable to the modern workplace and important elements in understanding the environment and behavior connections; but they are not new. One only need be reminded of the words of Aristotle (322 B.C.) to see that the application of suitable behaviors to a given situation is more than quick observation and delineation; it is truly an art form, layered in calculated sophistication. "Anyone can become angry, that is easy. But to be angry with the right person, to the right degree, at the right time, for the right purpose and in the right way - this is not easy"(Aristotle in Emotional Intelligence 2.0).

It is becoming increasingly clear that an organization's ability to direct apposite behavior to an intended audience, with skill and precision at the actual time it is needed, is perhaps the most promising frontier of next generation business. As work environments create increasing space for innovation and intellectual capitalism, the subtleties of advanced Emotional and Cultural Intelligence will undoubtedly provide the economic edge.

To understand how EB has evolved to the present, some of the early influencers of human-nature relationships should be examined. Human-nature 
relationships have often evolved on a parallel track. On one level the relationship stems from geographic and biological needs and responses; on a parallel level the human-nature relationship evolves along a continuum of spiritual and ethereal philosophies through to scientific theories. To assist in illustrating the parallel track, one can look to evolutionary patterns. Human survival is predicated on environmental adaptability. For example, in order to survive in geographic areas that were hot, arid regions, humans developed predatory hunter skill sets in order to satisfy biological requirements; in dense, lush, tropical environments, survival was predicated in part on the development of "gatherer" skill sets.

From a spiritual perspective, the idea of harmony between man and nature has been a core component of environmental adaptability in many cultures. Societies like ancient China and Native America, although vastly different cultures, shared a reverence for the earth and man's relationship to it. There was a core belief and understanding that land was the primary source of all living products and should be honored. These early ancestors were keenly aware of the cycles of the land, the subtleties of the seasons, the growth cycle of crops and live stock, and possessed a systemic belief that all things sacrificed for the good of man should be revered through the use of all elements of earth or animal that was sacrificed. The bond of the human-environment dependency was a very spiritual relationship that was manifested in all rituals and beliefs. This EB system had far reaching influence on the evolution of man.

Not all cultures, however, shared the same reverence for the delicate balance required of human behavior in relationship to the environment. Western 
Anthropocentric tradition, which was mainly influenced by Judeo-Christianity, exercised a philosophical belief in dominion. Specifically, man was viewed as the creation of a God who was believed to be the omnipotent Creator of both the heavens and earth and had endowed his creation the right to handle, conquer and manage the world (White, 1969). As this cultural belief system moved through time and geography, it continued to reinforce the notion that everything on the earth was generated by God specifically for the consumption of man.

This cultural system was eventually carried onto the prairies of the American Frontier. At its center, the system reinforced the power, and seemingly inherent right of man, to conquer and subdue the wild new world. Pioneers viewed the unknown wilderness and all of its inhabitants as the enemy (Niehardt, 1972). This belief system has continued to influence Western tradition and has had a marked influence on many of our contemporary behaviors including the utilization and subsequent exploitation of natural resources, civilization, urbanization, etc.

Competing with the "Pioneer" movement, Transcendentalism emerged as a blending of multiple philosophies that proposed to discover the nature of reality by researching the process associated with thought rather than the objects of sense experience (Webster's, 2011). Henry David Thoreau, Ralph Waldo Emerson, Margaret Fuller and many of their colleagues introduced the premise for Transcendentalism. In addition to the writings, spirituality, and societal perspectives they pursued, their work also embraced an eco-centric tradition that sprouted the idea of preservation and pastoral design. By the mid-1800's, many 
supporting the Transcendentalist movement were advocating the preservation of wild life areas. John Muir founded the Sierra Club, which became one of the most influential environmental preservation organizations in all of North America. The Sierra Club worked to leverage the use of natural and cultural resources without instilling damage to the physical environment. The first national park was established in 1864, mainly as a result of the unyielding efforts of Frederick Law Olmstead, a leading American landscape architect and planner. This lobbied preservation of land offered an influential building block for EB work. Later, Olmstead's eco-centric work led to the development of New York's Central Park as well as incorporating the use of green space at many university campuses around the United States. Olmstead greatly influenced the work of Benton Mackaye who, in turn, had a significant influence on elevating the importance of environment-behavior work through his efforts to create conservation, environmentalism, recreational and regional planning (Anderson, 2002). Although oppositional in their approach, Pioneerism and Transcendentalism influenced the evolution of environment-behavior thought and the manner in which North American land use, design, commerce and public policy began to emerge.

During World War II, the creation of the Civilian Public Service (CPS) left an unintended, but substantial, footprint on soon-to-be emerging EB studies. CPS provided religious conscientious objectors from groups including Mennonites, Amish and Quakers the ability to serve their country without engaging in military activity. From 1941 to 1947, almost 12,000 men joined the CPS and worked in forestry, soil conservation, fire fighting, agriculture, social services and mental 
health. Their non-violent pacifist behavior also promoted an organic, eco-centric, humanitarian approach to the development of the professions in which they served. A key contribution to the early beginnings of the EB movement was their work in psychiatric hospitals. By the end of 1945 , more than 2,000 CPS men worked in 41 institutions in 20 states (Gingerich, 1949). They experienced firsthand the horrendous conditions to which patients were subjected. Their strong objections to patient mistreatment fueled their determination to improve the conditions of psychiatric wards. They directed their activism toward sweeping changes for humane treatment of patients and drastic changes to the physical environment within mental institutions. Prior to this change, architects of hospitals had designed for structure, not human elements. After this societal shift, psychologists began to generate substantial data regarding the social needs of individuals and their corresponding behavior in order to provide input into the design process. Although limited in its initial impact, the architectural and political world took notice; the work was meaningful and began to take hold (Dyck, 1997).

By the time the United States emerged from World War II, pivotal changes in society influenced the materialization of formalized environment-behavior studies. A seismic shift came in the form of the Gl Bill, which opened the door for thousands of veterans to become first generation college graduates. Low interest loans for both mortgages and small-businesses provided a gateway for many to realize the "American Dream". Rapidly developing technologies provided the opportunity for households to have appliances, tools and cost efficient 
transportation that alleviated some of the time constraints of everyday life. It also led to the growth of personal lives, leisure time and the introduction of a widespread middle class.

Changes to the social and physical landscape of the 1950's and 1960's prompted significant growth and exploration within the social sciences. Psychology, ecology, sociology, anthropology, geography and design exploded with opportunity; their common threads began to pull the sciences together into a multi-disciplinary approach, coined Environment-Behavior studies (EB). The drive to further understand the balance, influence and co-existence of the environment and human behavior came into being in large part because of the pioneering work of five key scientists: Roger Barker, Edward Hall, Robert Sommer, Kevin Lynch and Christopher Alexander (Bechtel, 1997).

Barker was one of the first to attempt to develop an ecological perspective inside the discipline of psychology. He and his colleague, Herbert Wright, started the process of observing and recording the environmental behavior and actions of children at the Midwest Field Station, an observatory they founded in a small town west of Lawrence, Kansas where they both were professors (University of Kansas). The two social scientists brought psychological studies out of the traditional laboratory and into the real world. Their work paved the way for observational design (Barker, 1990).

Anthropologist Edward Hall contributed to the sciences the notion of social distance and personal space. His work launched the description and initial understanding of: 1) Personal Space: a individual's personal territory that is with 
them at all times, 2) Primary Territory: the primary place of retreat for its occupants, where occupants have a strong sense of ownership and invasion of this territory is often prohibited by law, for example, one's place of residence, 3) Secondary Territory: space that cannot be personalized to the extent that primary territory can be because they are not considered permanent and cannot be continuously occupied, for example offices or work space, and 4) Public Territory: territories that function based on formal regulations, the use of the space is restricted by laws, codes, customs and regulations. Examples would include parks, restaurants and shopping malls (Stewart-Pollack \& Menconi, 2005). Sommer also built on the work of Hall in his book entitled Personal Space: The Behavioral Basis of Design (Sommer, 1974). His work sought to explain what personal space is and how people go about protecting this space.

The work of Kevin Lynch focused on dissecting the way in which “urbanites" perceive, take in, and arrange spatial information (Lynch, 1964). His research engaged urban planners and designers in the process of thinking about how to make city planning "legible" for their occupants as well as for the visitor, so both parties are able to easily orient and navigate themselves in the urban setting. He identified three components of any urban image: 1) identity, 2) structure and 3) meaning, and further introduced "image elements" (paths, edges, districts, nodes, and landmarks) that are repetitively established to denote urban space. His work produced certain guiding principles in which urban designers could engage in order to improve the quality of life and experience for the cities' inhabitants and visitors. 
Christopher Alexander focused his architectural expertise and interest on the design and construction of buildings from the end user's perspective. He pushed to demystify the work of designing in an effort to empower the end users to design and build for themselves, their personal needs, and desires (Alexander, 1977). Furthermore, his work on pattern language emphasized that a pattern is essentially a way of approaching and solving a design problem; the more problems one has, the more patterns he needs to develop. The more patterns that are developed, the richer the design dialogue becomes and the greater the opportunity for creative order.

The efforts of these five environment-behavior forefathers provided intellectual space where their multi-disciplinary efforts could be woven together to create a unique approach for examining the human experience as a function of the physical environment in which they inhabited. In addition to the significant impact of a changing societal landscape, their collective body of work also paved the way for a developing a focus on the worker and the work environment. J. Douglas Porteous has also been an under recognized yet powerful influence on workplace study as a result of his efforts around cognitive mapping. His work can be viewed as some of the early stepping-stones to elementary $\mathrm{OD}, \mathrm{OB}$ and $\mathrm{EB}$ processes and concepts. He helped to champion the importance of understanding how information is managed within the human experience and expressed in human behavior by applying the method in which information from the environment is collected, processed though the brain (cognition), and output as demonstrable behavior (Porteous, 1977). 
More recently two individuals, Eric Sundstrom (psychology) and Janetta McCoy (interior design), have paved new ground for environment and behavior research. Eric Sundstrom's work has evolved since the start of his academic career to include his current EB research focus on the relationship between interpersonal interaction in small groups, group performance and viability in work settings. His focus on group interaction process variables and organizational context factors such as reward systems, culture and environment has been influential in workplace studies and application, including the relationship between features of physical environments, individual experience and interpersonal relationships at work (Department of Psychology, 2012). Janetta McCoy's work derives from an interior design background and has evolved into a focus on the work environment, specifically places of creativity in the physical workspace and intellectual performance and stressors in the workplace. McCoy focuses on cross dimensional research in the areas of design, social psychology, and environment-behavior studies (Department of Interior Design, 2010). Both researchers come to environment-behavior work from different perspectives and expertise, but they offer a substantial amount of knowledge and system indicators for workplace design, productivity and influence.

A review of some of the historical influencers, both societal and scientific, helps to identify the conceptual elements of Organization Development (OD), Organizational Behavior (OB), Organizational Systems (OS) and EnvironmentBehavior (EB) and further demonstrates how they intersect. Although each of these scientific domains has distinct approaches to theory, research and reporting 
on the human experience, they all clearly share foundational and academic characteristics that translate into the contemporary workplace. All four provide a complimentary and layered application to work environment design and modern workplace theory. Attribute items like workplace assessments, workflow analysis, recruitment and retention, company culture, training and development, the physical environment and employee job satisfaction all draw from the $\mathrm{OD}, \mathrm{OB}$, $\mathrm{EB}, \mathrm{OS}$ disciplines. This theoretical work presents a unique opportunity to further dissect the characteristics of financially successful businesses that are steadfast in their commitment to promoting excellent employee work environments.

The purpose of this dissertation is to investigate the relationship between $\mathrm{OD}, \mathrm{OB}, \mathrm{EB}$ attributes in the 'Place to Work' Index (PWI) as they relate to the OS attributes in the Organizational Systems Assessment Survey (OSAS). The research examines the statistically related components to further establish an integrated workplace model that can be applied in cross-industry settings leading to advanced recommendations for EB changes that endorse the traits of successful, employee-centric workplaces and support the organizational system preferences of the workforce. 


\section{Chapter Three}

\section{METHODS}

This chapter is organized as follows:

(a) Research Design

(i) 'Place to Work' Index

-Fortune 500 Companies

-Top 100 Best Places to Work

-Survey of Organizational Excellence

-Covey's 7 Habits Benchmark

(ii) Organizational System Assessment Survey

-Family Regime Assessment Scale (FRAS)

-Organizational System Assessment Scale (OSAS)

(b) Developing the Survey Instrument

(c) Data Collection and Management

(d) Multi-attribute Utility Technology (MAUT) Analysis Plan

\section{$\underline{\text { Research Design }}$}

As noted in Chapter 1, surveys have long been a powerful management tool used to obtain data that assists decision makers in shaping the strategic goals of the business. Business surveys traditionally support organizations in obtaining data in three general categories: 1) Culture and Leadership, 2) Products and Services and/or, 3) Competitiveness and Efficiencies. Within the realm of workplace surveys limited instruments exist that focus primarily on the workplace attributes of companies that are identified as highly successful corporations and deemed to have the qualities that create an excellent workplace for its employees. Accordingly, the 'Place to Work' Index was developed using attributes of highly successful, employee-centric organizations across a variety of industries.

This dissertation work combines the 'Place to Work' Index with the Organizational Systems Assessment Survey to provide a comprehensive, yet easily 
administered diagnostic tool that measures the interaction and preferences between environment and personal characteristics in a context of the qualities of highly successful employer organizations. This multi-dimensional tool can be applied in a variety of workplace settings, including an array of industries and varying company sizes to provide employers with opportunities to identify the strengths and weaknesses of their current work environment as benchmarked to the attributes of the combined Index and Assessment. Perceptions of 'Actual' workplace conditions and 'Ideal' conditions are obtained in order to assess perceptual conosance or dissonance. This method yields a measure of the environment/ behavior 'fit' between perceptions of 'Actual' and 'Ideal' workplace.

'Place to Work' Index (PWI)

The 'Place to Work' Index and corresponding workplace attributes (security, integrity, reciprocity, citizenship, authenticity) stemmed from four substantive settings: Fortune 500 companies, Top 100 Great Places To Work, the Survey of Organizational Excellence, and Franklin Covey's 7 Habits of Highly Successful People.

In American corporations, multiple financial indicators point to a company's stability and financial status. To identify financially thriving companies for the development of the 'Place to Work' Index, the Fortune 500 listing was employed. The Fortune 500 is an annual listing published by Fortune magazine that lists the top 500 U.S. privately held and public corporations as ranked by their gross revenue after adjustments made by Fortune to exclude the impact of 
excise taxes. Although there are other financial listings used in the business industry, the Fortune 500 listing has endured since 1955, in part because of the unbiased revenue based criteria, which is considered to be less volatile than other competitor indexes. The top 500 listing was cross referenced to Fortune magazine's Top 100 Places to Work. Companies that are at least seven years old with more than 1,000 U.S. employees were eligible to participate. An extensive survey and culture audit was used to select the top 100 employers. The survey included items related to employee attitudes about management's credibility, job satisfaction, and camaraderie. The culture audit included questions related to pay and benefit programs and open-ended questions about hiring practices, diversity efforts, internal communication, training programs, and recognition programs. Companies representing a wide variety of industries, including retail, food and beverage, hotel/real estate, insurance, financial, information technology and telecommunications were listed on both the Fortune 500 and Top 100 Places to Work from 2006-2010 and were selected for review.

In addition to the Fortune listings, two other surveys were reviewed: 1) The University of Texas' Survey of Organizational Excellence, and 2) Franklin Covey's 7 Habits Benchmark. The Survey of Organizational Excellence (SOE) has been used to assess the perceptions of thousands of individuals, primarily in government agencies, to capture opinions and needs related to aspects of the total work environment. Because government workplaces are largely service-based, the survey emphasis was focused on promoting excellence through employee engagement and accountability. The survey has three primary 
environmental foci: the vital role every employee must play, continuous focus on more effective and efficient ways of getting work accomplished, and candor among all employees toward building a quality organization. The survey focuses on five core workplace dimensions (work, accommodations, organization, information, and personal) and 20 corresponding constructs that focus on the environment-behavior attributes (supervisor, fair pay, change oriented, internal, job satisfaction, fairness, work setting, goal oriented, availability, time and stress, team, benefits, holographic, external, burnout, diversity, employee development, strategic, empowerment, quality) (Table I).

Franklin Covey's 7 Habits Benchmark is a multi-dimensional tool often referred to as a 360 degree assessment that reports from multiple perspectives including, self, peers, direct reports, and boss. The categories that are covered correspond with Franklin Covey's 7 Habits of Highly Successful People, which stems from work that began in the 1980's and has developed through research and thousands of subsequent surveys and interviews. The dimensions are referred to as the habits of successful behavior. The constructs encapsulate the meaning, behavior and actions associated with the corresponding dimensions. The overall attributes are: taking initiative and responsibility, clarifying goals and values, planning, prioritizing and executing, finding mutually beneficial solutions, respecting others, listening, communicating effectively, teamwork, strengths based leadership, work/life balance, planning, strategy and problem solving(Table II). 
Dimension

Work
Work
Work
Work
Accommodations
Accommodations
Accommodations
Accommodations
Organization
Organization
Organization
Organization
Organization
Information
Information
Information
Personal
Personal
Personal
Personal

Construct

Supervisor
Fairness
Team
Diversity
Fair Pay
Work Setting
Benefits
Employee Development
Change Oriented
Goal Oriented
Holographic
Strategic
Quality
Internal
Availability
External
Job Satisfaction
Time and Stress
Burnout
Empowerment

Organizational Systems Assessment Survey (OSAS)

The development of the OSAS and corresponding workplace regimes are derived from two areas of research and application: the Family Regime Assessment Scale (FRAS) and the Organizational Regime Assessment Scale (ORAS). 


\section{Table II: 'Seven Habits Benchmark' Dimension and Construct Items}

Dimension

Be Proactive
Begin With the End in
Mind

Put First Things First

Think Win-Win

Seek First to Understand Then to Be Understood

Synergize

Sharpen the Saw

\section{Construct}

Take initiative in life by realizing your decisions (and how they align with life's principles) are the primary determining factor for effectiveness in your life. Taking responsibility for your choices and the subsequent consequences that follow.

Self-discover and clarify your deeply important character values and life goals. Envisioning the ideal characteristics for each of your various roles and relationships in life.

Planning, prioritizing, and executing your week's tasks based on importance rather than urgency. Evaluating if your efforts exemplify your desired character values, propel you towards goals, and enrich the roles and relationships elaborated in Habit 2.

Genuinely striving for mutually beneficial solutions or agreements in your relationships. Valuing and respecting people by understanding a "win" for all is ultimately a better long-term resolution than if only one person in the situation had gotten their way.

Using empathetic listening to be genuinely influenced by a person, which compels them to reciprocate the listening, take an open mind to being influenced by you, which creates an atmosphere of caring, respect, and positive problem solving.

Combining the strengths of people through positive teamwork, so as to achieve goals no one person could have done alone. How to yield the most prolific performance out of a group of people through encouraging meaningful contribution, and modeling inspirational and supportive leadership.

The balancing and renewal of your resources, energy, and health to create a sustainable long-term effective lifestyle. Allow yourself to grow by maintaining a balanced program in the four areas of your life: physical, social/emotional, mental, and spiritual. 
The FRAS was developed based on the premise that an individual interprets and understands life phenomena in uniquely different ways. The person's experiences and perceptions, when combined within a family work together to create a "regime" or preferred way of knowing, acting and interacting within the organism or system. In their research, Imig and Phillips identified 32 Family Regime combinations that led to the creation of the Family Regime Assessment Scale (Imig, 1992).

Phillips' continued work on theoretical relevance of the regime theory in other environment-behavior settings discovering application for the regime theory within the workplace. By reordering the theoretical premise of the FRAS into the work environment, and employing the behavioral basis of design, focusing primarily on the Ecological Equation which is $B=P, E,(P \times E), B=$ Outcome Behaviors, $\mathrm{P}=$ Personal Characteristics, $\mathrm{E}=$ Environmental Characteristics, $\mathrm{P} \times \mathrm{E}=$ Interaction between Environment and Personal Characteristics, Phillips developed the Organizational Regime Assessment Survey (ORAS) and subsequently the modified version that is used in this dissertation, the Organizational Systems Assessment Survey (OSAS).

The work is predicated on the organization's 'world view' or 'regime' across four critical dimensions within two conceptual domains resulting in a predominant regime (open, closed, random, synchronous). The theoretical underpinnings of regime derive from Family Paradigm Theory, which contextually explains that, "family systems, like all social systems, are organizationally complex, open, adaptive, and information-processing systems." (Kantor and Lehr p 10). It is 
through this unique framework that order and meaning are established into a collective family life, adjusting to one another, establishing a level of consistency and reliability that pulls the unit into commonality. This patterned behavior stems from day-to-day activities providing comparison points of systemic patterns that are categorized at three levels referred to as paradigms, process and regimes (Demerath and Peterson, 1967).

Paradigm is the perspective that the system understands, or perceives itself to be. It comes from the organism's collective attitudes, values, motivators and assumptions and creates the unspoken guidelines for behavior. Processes denote the manner in which activities are carried out and regimes evolve to regulate behavioral manifestations that are in line, or congruent with, the organism's paradigm. Regimes are the categorical reaction or norms of a given unit or system. This behavioral disposition results from the group's process and response mechanisms.

The Organizational Systems Assessment Survey (OSAS) focuses on the work environment from an organic systems perspective. It assesses respondents' perceptions and preferences of their respective workplaces through four critical dimensions (control, content, meaning and affect), linking the complexity of environmental factors associated with the organization-environment habitat. Kantor and Lehr (1975) and Constantine (1986) developed a critical eight-point dimension framework to further categorize and interpret organizational behavior and workplace processes. The eight dimensions are bifurcated into physical (access) and informational (target) categories as referenced in Table III below. The 
dimensional framework applied in a weighted manner to the constructs of open, random, synchronous and closed provides categorical meaning within the OSAS, and gives a consistent methodology to employ within the work environment.

Table III: Access and Target Dimensions

\begin{tabular}{|l|l|}
\hline \multicolumn{2}{|l|}{ Access Dimensions } \\
\hline Time & $\begin{array}{l}\text { Responsible for pace, sequence and frequency of activities in order } \\
\text { to plan for and attain goals. }\end{array}$ \\
\hline Energy & $\begin{array}{l}\text { The required strength and intensity needed to devise and execute } \\
\text { the needs of the system or organism. }\end{array}$ \\
\hline Space & $\begin{array}{l}\text { Defines the associated meaning of interpersonal relationships } \\
\text { through the establishment of spatial boundaries of individuals and } \\
\text { things. }\end{array}$ \\
\hline Material & $\begin{array}{l}\text { The mechanism used to acquire, accept and reject the material } \\
\text { world through the association of meaning and value. }\end{array}$ \\
\hline Target Dimensions \\
\hline Control & $\begin{array}{l}\text { Mechanism used to regulate processes, beliefs, items and decisions } \\
\text { in order to achieve goals and satisfy needs. }\end{array}$ \\
\hline Affect & $\begin{array}{l}\text { The reliance on how feelings are expressed and received resulting } \\
\text { in varying levels of intimacy. }\end{array}$ \\
\hline Meaning & $\begin{array}{l}\text { Values, attitudes, worldviews, words, symbols and icons that } \\
\text { establish the system's identity and significance. }\end{array}$ \\
\hline Content & $\begin{array}{l}\text { Formulates and processes information in an effort to solve } \\
\text { problems and interpret surroundings. }\end{array}$ \\
\hline
\end{tabular}

The dimensions are weighted against the system's regime or organizational disposition that is established through four observable behavior types (Open, Closed, Random, Synchronous). These behavior types constitute theoretical norms that permit both family organisms and organizations to be more fully understood and deciphered. Through a complex make up, the whole of the organism is much greater than the sum of its parts. Constantine (1993) appropriately reflects this sentiment by denoting that all human systems can be understood through 
pragmatic theory. The fundamental building blocks of each regime must be considered and addressed according to their unique characteristics and perspectives. The individual vantage points of regime derive from: defining and maintaining boundaries, individual interest versus the interest and identity of the group, stability versus change over a period of time, information and communication management, and views pertaining to roles and structure.

\section{Closed System (Regime)}

A closed system is built on a formal hierarchy wherein the typical power structure lies with the authority figure or authority status. It regulates the organism through structured rules, specific principles and customs. These regulations are manifested through the group's identification with security, stability and balance. The focus of reliance is on time tested responses that guide future decisions; Past behavior predicts future success._This system can be identified through its formality, stability, consistency, and traditional approach demonstrated through authoritative and conservative behaviors and traits (Kantor and Lehr, 1975; Constantine 1986).

\section{$\underline{\text { Random System (Regime) }}$}

The random system, also referred to as the anti-thesis, derives from a minimalist organizational structure. The system openly seeks and incorporates spontaneity and creativity amidst change. On the surface the system may appear to be fraught with disorganization and unpredictability, unbalanced in its ability to move through decisions and organizational needs. However, the key to this system's ultimate success lies in its ability to harness the chaos through the 
magnification of personal freedom, differentiation and self expression. These traits have the ability to lead to a spontaneous, creative, energetic, individualistic and explorative path, creating an environment that is conducive to autonomous decision making and personal motivation and responsibility (Kantor and Lehr, 1975; Constantine 1986).

\section{Open System (Regime)}

The Synthesis, or open regime, is an environment that is both flexible and adaptable. It garners systemic strength through its ability to be in flux and flexible within any given set of circumstances. Open communication is a core aspect of this system's success, often times the outcome is a product of the group's ability to discuss, negotiate and integrate the opinions and objectives of the many to solidify the needs of the overall group. This system can be described as expressive, sincere, responsive, tolerant,_challenging and relevant (Kantor and Lehr, 1975; Constantine 1986).

\section{Synchronous System (Regime)}

The Synchronous system, also referred to as the anti-synthesis, is structured through unspoken norms that translate into rules of engagement and behavioral traits which the group adheres to for stability and success. There is an absence of detailed communication and interaction. Rather, the organism manifests its identity through behaviors that translate into peace, harmony and control. The demonstration of emotions are limited in scope, exacting reserved behavior and creating a system that is precise, exact, controlled, measured assured, certain and wise(Kantor and Lehr, 1975; Constantine 1986). 
These systems interact within the workplace to establish predominant and sub-categorized behavior patterns and observable regimes.

\section{Developing the Survey Instrument}

The survey, entitled Organizational Learning Survey: University of Missouri Extension, was designed to include the work of five researchers assessing multiple environment-behavior aspects of the workplace. For the purposes of this dissertation, evaluation of the data and analysis will be restricted to the interaction of the OSAS, PWI and respondent demographics. The survey was divided into four sections:

- The OSAS (Organizational System Assessment Survey) - assesses both the perceived ACTUAL and IDEAL organizational perceptions,

- The SIRCA (Great Place to Work Index) - assesses both the perceived ACTUAL and IDEAL 'Great Place to Work' characteristics,

- The EPI (Environmental Preferences Index) - assesses both the perceived ACTUAL and IDEAL environmental preferences required to perform assigned tasks,

- The Space Use Inventory - assesses the perceived IDEAL environmental characteristics required to accomplish one's work.

- Demographic information - (e.g., respondent age, gender, length of employment, job title, academic discipline, current Extension region, etc.).

The survey instrument was developed to capture levels of preference

(IDEAL) versus what was perceived to be actually occurring in the respective work environment (ACTUAL) using a 10-point scale. The respondents were asked to assign a value to the level of importance from a list of possible responses. They first selected and assign a value of 10 to only one response for the (ACTUAL) 
condition that best described their opinion, then assigned a value from 0 to 9 to each of the remaining answers in the (ACTUAL) value list comparing it to the one they identified as best describing their opinion. They then repeated the procedure, addressing the statements from their perceived (IDEAL) condition. Demographic information that would assist in data analysis was also included. After the initial construction of the instrument, a preliminary draft of the instrument was reviewed by a cross-section of working adults. The outcome of the review resulted in the revising and re-ordering a small number of the survey items.

Using the Multi-attribute Utility Technology (MAUT) (Edwards \& Newman, 1982), the research linked work environment preference (OSAS) to the SIRCA attributes by order of importance and by order of what is perceived to be actually occurring in their current work environment. This ordering provided a ranking of priorities for the organization to be used as a potential roadmap for planning and execution of employee-centric components that matter most to its present workforce. The raw scores were normalized by transforming them into their proportional properties (i.e., the percent weight of each response in comparison with the other related responses within each survey item).

\section{Participant Demographics and Data Collection}

Survey-Monkey, an online survey development software, was used to transfer the survey instrument into an electronic format. The electronic format provided the opportunity to use web-based survey distribution to obtain and 
retain information anonymously and without geographic limitations. The data was stored on the Survey-Monkey site utilizing a secure socket layer (SSL), which means that the traffic between the user's (respondent's) browser and the SurveyMonkey website is encrypted. Additionally, the data was stored in a format that is compatible with IBM's SPSS (Statistical Package for Social Sciences) software that was used for statistical analysis.

The survey was distributed through the University of Missouri E-mail system to a distribution list of 1,068 University Extension employees. The survey took approximately 15 minutes to complete. Each electronic page of the survey had either radio dial buttons that respondents could "click" on in order to submit their response to each item, a drop down box for selection of predetermined information, or a "free text" fill-in area. Additionally, each page had an indicator of the percentage of the total survey respondents had completed with each item. The main objective with the widespread survey distribution was to obtain a selfselected sample of at least 200 responses from varying programs and positions within the Extension program in order to provide for a sufficiently large sampling to complete statistically valid analyses. At the close of the three week data collection period a total of $n=411$ individuals had completed at least a portion of the survey. Copies of the survey instrument and informed consent are included in the Appendix. 


\section{Multi-Attribute Utility Technology (MAUT)}

The Survey (OSAS) and Index (PWI) research tools have both qualitative and quantitative attributes, the MAUT approach provided a single, integrated framework from which to work and report. By using utility or value functions, the MAUT permitted the transformation of diverse criteria, like that found in both the PWI and the OSAS, and move them into one common scale or value. The tool is rooted in three assumptions: 1 ) the survey participants are rationale (able to read and respond to criteria in a categorized method), 2) the survey participants have ideal knowledge (they are able to participate in and judge their EB experience) and 3) the survey participants are consistent in their judgments (they are able to rank or categorize in order of preference and/or perception). Because the goal of the MAUT was to provide a systemic expression of a more complex set of attributes, the criteria are focused on maximizing utility or value. This compensatory method fit nicely into the goals of the dissertation research. The step-by-step analysis plan for this dissertation can be found in the Appendix.

\section{The Sample}

To provide a framework for conceptualizing the sample's demographic characteristics, the following overview provides a snapshot of the data. A specific breakdown of all demographic characteristics is detailed in the Analysis chapter. Of the 411 individuals who responded, over 31 percent worked on the Columbia Campus, almost 22 percent worked in the School of Human Environmental Sciences, 53 percent of the respondents were females, the average tenure at MU 
Extension was 13.5 years, and the mean respondent age was just under 50 years old. 


\section{Chapter Four}

\section{FINDINGS AND CONCLUSIONS}

The findings of this research are organized in this chapter as follows:

(a) A demographic profile of the sample

(b) 'Place to Work' (SIRCA) survey items examined by principal components analysis

(i) Survey items identified with each factor - factor loadings, items excluded

(ii) Factor analysis of three remaining constructs (IDEAL and ACTUAL)

(c) 'Place to Work' and OSAS constructs examined using Multi Attribute Unit Analysis (MAUT) patterning

(d) OSAS and 'Place to Work' cross-examined

(e) Discussion and Limitations of the Study

(f) Conclusion

(g) Future Research

\section{Demographic Profile}

The sample population derived from the University of Missouri Extension employee base $(n=1068)$. The actual number of respondents was 38 percent of the available population $(n=411)$. The most frequently reported response for region or campus location $(n=324)$ was Columbia Campus accounting for 31.4 percent of the respondents $(n=129)$, followed by Urban Region with 8.8 percent $(n=36)$, Southwest Region with 7.8 percent $(n=32)$, and Northeast Region with 6.6 percent $(n=27)$, East Central Region with 6.1 percent $(n=25)$ with Southwest Region with 5.1 percent $(n=21)$, with Northwest Region with 4.9 percent $(n=20)$, with West Central Region with 4.6 percent $(n=19), 2.7$ percent $(n=11)$ of the respondents were not assigned to a Region or Campus, 87 respondents did not 
identify a location, and Kansas City, Rolla and Saint Louis Campuses all came in below one percent of the respondents.

The most frequently reported response for survey items related to the individual's professional discipline area $(\mathrm{n}=89)$ was Human Environmental Sciences accounting for 21.7 percent of the respondents; followed by Agriculture \& Natural Resources with 12.9 percent $(n=53) ; 4-H /$ Youth with 11.2 percent $(n=46)$; Administration/Management category with 9.5 percent $(n=39)$; Community Development with 6.6 percent $(n=27)$, Business Development with 6.3 percent $(n=26)$, Continuing Education with 5.1 percent $(n=21)$, and Clerical/support Staff with 4.4 percent $(n=18), 22.4(n=92)$ percent elected not to identify their respective discipline.

The mean response for length of employment was 13.53 years working within Extension. The $25^{\text {th }}$ percentile was five years, the $50^{\text {th }}$ percentile was reported at 11 years, and the $75^{\text {th }}$ percentile was 20.25 years. A demographic review of the data as it relates to gender resulted in 26.8 percent $(n=110)$ male respondents 53 percent $(n=218)$ female respondents and 20.2 percent $(n=83)$ participants that elected not to disclose their respective gender. The mean age response was 49.76 years, the $25^{\text {th }}$ percentile was 41 years, the $50^{\text {th }}$ percentile was reported at 53 years, and the $75^{\text {th }}$ percentile was 59 years.

\section{Survey Instrument}

The survey instrument was developed to capture levels of preference (IDEAL) versus what was perceived to be actually occurring in the respective work environment (ACTUAL) using a 10-point scale. The respondents were asked to 
assign a value to the level of importance from a list of possible responses. They first selected and assign a value of 10 to only one response for the (ACTUAL) condition that best described their opinion, then assigned a value from 0 to 9 to each of the remaining answers in the (ACTUAL) value list comparing it to the one they identified as best describing their opinion. They then repeated the procedure, addressing the statements from their perceived (IDEAL) condition. The Multiattribute Utility Technology (MAUT) tool linked work environment preference (OSAS) to the SIRCA attributes (Security, Integrity, Reciprocity, Citizenship, Authenticity) by order of importance and by order of what is actually occurring in their current work environment. The raw scores were normalized by transforming them into their proportional properties (i.e., the percent weight of each response in comparison with the other related responses within each survey item).

\section{Extension' Survey Items}

The final version of the survey instrument had 23 survey items, including 8 demographic items. The survey included the work of five researchers assessing multiple environment-behavior aspects of the workplace. For the purposes of this dissertation, evaluation of the data and analysis was restricted to the interaction of the OSAS, PWI and respondent demographics. The survey was divided into four sections:

- The OSAS (Organizational System Assessment Survey) - assesses both the perceived ACTUAL and IDEAL organizational perceptions,

- The SIRCA (Great Place to Work Index) - assesses both the perceived ACTUAL and IDEAL 'Great Place to Work' characteristics, 
- The EPI (Environmental Preferences Index) - assesses both the perceived ACTUAL and IDEAL environmental preferences required to perform assigned tasks,

- The Space Use Inventory assesses the perceived IDEAL environmental characteristics required to accomplish one's work.

- Demographic information - (e.g., respondent age, gender, length of employment, job title, academic discipline, current Extension region, etc.).

The survey instrument was developed to capture levels of preference (IDEAL) versus what was perceived to be actually occurring in the respective work environment (ACTUAL) using a 10-point scale. The respondents were asked to assign a value to the level of importance from a list of possible responses. They first selected and assign a value of 10 to only one response for the (ACTUAL) condition that best described their opinion, then assigned a value from 0 to 9 to each of the remaining answers in the (ACTUAL) value list comparing it to the one they identified as best describing their opinion. They then repeated the procedure, addressing the statements from their perceived (IDEAL) condition. The Multiattribute Utility Technology (MAUT) tool linked work environment preference (OSAS) to the SIRCA attributes (Security, Integrity, Reciprocity, Citizenship, Authenticity) by order of importance and by order of what is actually occurring in their current work environment. The raw scores were normalized by transforming them into their proportional properties (i.e., the percent weight of each response in comparison with the other related responses within each survey item). 


\section{‘Place to Work' Index}

The five factors and corresponding survey items were grouped into overarching business tenants that constitute the 'Place to Work' Index. The index items (Dimensions) and definitions (Constructs) are arranged and presented in Table IV.

\section{Table IV: 'Place to Work' Dimensions and Constructs (SIRCA)}

\begin{tabular}{|c|c|}
\hline Dimension & Construct \\
\hline Security & $\begin{array}{l}\text { Ensuring the company's financial strength and } \\
\text { the presence of security and stability in both the } \\
\text { physical (office/workplace) and business } \\
\text { environment (pay, policies, practices) }\end{array}$ \\
\hline Integrity & $\begin{array}{l}\text { Behaving with integrity, building cooperative } \\
\text { work systems by placing faith and trust in each } \\
\text { other }\end{array}$ \\
\hline Reciprocity & $\begin{array}{l}\text { Valuing and nurturing the mutual benefit of a } \\
\text { balanced Employer/Employee relationship }\end{array}$ \\
\hline Citizenship & $\begin{array}{l}\text { Dedicated to doing the right thing in business } \\
\text { dealings, in the work environment, and in the } \\
\text { community }\end{array}$ \\
\hline Authenticity & $\begin{array}{l}\text { Maximizing human interest, fortifying diverse } \\
\text { environments where empathy, solidarity, and } \\
\text { tolerance is practiced and individuality is } \\
\text { acknowledged }\end{array}$ \\
\hline
\end{tabular}




\section{Principal Component Analysis Results}

The "Place to Work" Index (SIRCA) survey items were analyzed using principal component analysis extraction and a Varimax rotation method with Kaiser normalization. The rotation converged in six iterations and the rotated factor matrix established three factors for consideration. The survey items and corresponding factor loadings are presented in Table V (ACTUAL). For the purposes of this analysis, only the factor loadings in each category that had the highest statistical significance were retained for subsequent analyses. This eliminated the constructs Reciprocity and Authenticity.

Table V: 'Place to Work' (SIRCA) Survey Items and Factor Loadings

\begin{tabular}{|c|c|c|c|}
\hline \multirow{2}{*}{ Survey Item } & \multicolumn{3}{|c|}{ Factor Loadings } \\
\hline & 1 & 2 & 3 \\
\hline Security & -.555 & .152 & .223 \\
\hline Integrity & .140 & -.688 & .210 \\
\hline Reciprocity & .303 & .497 & .267 \\
\hline Citizenship & -.022 & .060 & -.779 \\
\hline Authenticity & .499 & .102 & .136 \\
\hline
\end{tabular}

The remaining items Security, Integrity and Citizenship were subsequently re-analyzed using factor analysis for the three constructs. Descriptive statistics indicate a difference in overall mean scores for ACTUAL in comparison to IDEAL (Table VI). 
Table VI: SIC Constructs and Mean Comparison - ACTUAL to IDEAL

\begin{tabular}{|l|r|r|r|}
\hline \multirow{2}{*}{ Construct } & \multicolumn{3}{|c|}{ Mean Comparison } \\
\cline { 2 - 4 } & ACTUAL & IDEAL & \multicolumn{1}{c|}{ Difference } \\
\hline Security & 7.56 & 8.72 & 1.16 \\
Integrity & 7.24 & 8.98 & 1.74 \\
Citizenship & 7.60 & 8.73 & 1.13 \\
\hline
\end{tabular}

The MAUT was applied to the remaining constructs Security, Integrity and Citizenship. The application was employed to establish a pattern of ACTUAL and IDEAL responses as it relates to a comparison of the mean of the overall survey sample. The resulting patterns are contained in Table VII and Table VIII. The patterns that are noted in Table VII (right most column) were obtained through a comparison of the respondent's ACTUAL responses to the mean response of the sample population. The patterns (right most column) in Table VIII were the outcome of comparing the respondent's IDEAL response to the overall sample population mean response.

Table VII: SIC Pattern Response Frequency- ACTUAL

\begin{tabular}{|l|r|r|r|}
\hline \multirow{2}{*}{ MAUT Pattern ACTUAL } & \multicolumn{3}{|c|}{ Index } \\
\cline { 2 - 4 } & Frequency (n) & Percent & Pattern \\
\hline & & & \\
Integrity & 70 & 17.0 & $\mathrm{I}$ \\
Citizenship & 59 & 14.4 & $\mathrm{C}$ \\
Integrity and Citizenship & 59 & 14.4 & $\mathrm{IC}$ \\
Security & 59 & 14.4 & $\mathrm{~S}$ \\
Security and Integrity & 57 & 13.9 & $\mathrm{SI}$ \\
Security and Citizenship & 29 & 7.1 & SC \\
\hline
\end{tabular}


Table VIII: SIC Pattern Response Frequency - IDEAL

\begin{tabular}{|l|r|r|c|}
\hline \multirow{2}{*}{ MAUT Pattern IDEAL } & \multicolumn{3}{|c|}{ Index } \\
\cline { 2 - 4 } & $\begin{array}{c}\text { Frequency } \\
(\mathrm{n})\end{array}$ & Percent & Pattern \\
\hline Security & 92 & 22.4 & $\mathrm{~S}$ \\
Integrity & 62 & 15.1 & $\mathrm{I}$ \\
Citizenship & 59 & 14.4 & $\mathrm{C}$ \\
Integrity and Citizenship & 45 & 10.9 & $\mathrm{IC}$ \\
Security and Citizenship & 43 & 10.5 & $\mathrm{SC}$ \\
Security and Integrity & 40 & 9.7 & $\mathrm{SI}$ \\
\hline
\end{tabular}

A quartile analysis was completed for respondent demographics, of which, a detailed summary can be found in the Appendix. While strong demographic indicators were not established, there were some areas of data reporting that are noteworthy. Specifically, for age related responses, individuals in the lower half of the demographics (under age 53) reported an IDEAL work environment focused most on Security, while the upper half of the reporting individuals (up to age 79) reported their IDEAL work environment being focused most on Citizenship. Women were most aware of Integrity and Citizenship in their respective work environments, but preferred the attribute of Security. Men reported the presence of Integrity in the workplace, but similar to their female counterparts, also preferred Security. When analyzing patterns based on years of service within MU Extension, the respondents who had 0-20 years of service most frequently preferred an environment that provided Security. Those who had worked at the University for over 20 years reported an IDEAL environment as one that had Integrity.

A review of the IDEAL work environment from the perspective of gender indicated that both men and women overwhelmingly preferred Security in the 
workplace, as opposed to any other SIRCA combination. Regionally, respondents indicated that there was a majority presence of Integrity, but the IDEAL environment remained Security.

\section{'Organizational System Assessment Survey' (OSAS)}

The four dimensions and constructs of the OSAS (Open, Random, Closed, Synchronous) are described in Table IX.

\section{Table IX: 'Organizational System Assessment' (OSAS) Dimensions and Constructs}

Dimension
Open
Random
Synchronous

\section{Construct} An environment that is both flexible and adaptable. Strength is obtained through flexibility in any given set of circumstances

Derives from a minimalist structure. The system openly seeks and incorporates spontaneity and creativity amidst change

The system's environment is built on formal hierarchy. The power base lies within the authority figure or status

This environment is structured through unspoken norms that translate into rules of engagement and behavioral traits which the group adheres to for stability and success

\section{MAUT Application of the OSAS by Demographics}

The MAUT was applied to the weighted OSAS constructs measuring four target domains: control, affect, content and meaning. The mean resulting patterns for ACTUAL and IDEAL for each item are categorized below by overall responses. The patterns are contained in Table X. A detailed summary can be found in the Appendix. 
Table X: OSAS Mean Pattern ALL RESPONSES- ACTUAL and IDEAL

\begin{tabular}{|l|c|c|c|c|c|c|c|c|}
\hline $\begin{array}{l}\text { Mean Pattern } \\
\text { ACTUAL and } \\
\text { IDEAL }\end{array}$ & \multicolumn{8}{|c|}{ OSAS Domains by Overall Sample ( $\mathrm{n}=411)$} \\
\cline { 2 - 10 } & $\begin{array}{c}\text { Control } \\
\text { Actual }\end{array}$ & $\begin{array}{c}\text { Control } \\
\text { Ideal }\end{array}$ & $\begin{array}{c}\text { Affect } \\
\text { Actual }\end{array}$ & $\begin{array}{c}\text { Affect } \\
\text { Ideal }\end{array}$ & $\begin{array}{c}\text { Content } \\
\text { Actual }\end{array}$ & $\begin{array}{c}\text { Content } \\
\text { Ideal }\end{array}$ & $\begin{array}{c}\text { Meaning } \\
\text { Actual }\end{array}$ & $\begin{array}{c}\text { Meaning } \\
\text { Ideal }\end{array}$ \\
\hline $\begin{array}{l}\text { Mean } \\
\text { Standard }\end{array}$ & 5.80 & 5.77 & 5.06 & 5.86 & 4.51 & 5.21 & 5.14 & 5.17 \\
$\begin{array}{l}\text { Seviation } \\
\text { S.015 }\end{array}$ & 5.304 & 4.868 & 4.879 & 4.871 & 4.488 & 5.110 & 5.077 \\
\hline
\end{tabular}

\section{MAUT Application of the OSAS and 'Place to Work' Combined}

The four target domains: control, affect, content and meaning did not result in establishing a strong patterning for ACTUAL and IDEAL for each item. A detailed summary of the cross examination analysis of OSAS and 'Place to Work' is also found in the Appendix.

From this analysis a substantive aspect of the dissertation research was established. The most significant data point for the Extension respondents presents itself in the cross reference comparison of the most frequently occurring pattern for IDEAL for both the OSAS and PWI. Across all domains (Control, Affect, Content and Meaning) the most frequent response with regard to the IDEAL work environment was Closed-Synchronous and Security in each of the four domains (Table XI).

This indicates that for the most frequently patterned responses, respondents perceived an optimal work environment being one where individuals are comfortable working in a structured atmosphere that relies on positional authority for decision making, planning, order and responsibility. The optimal workplace would thrive on consistent behavioral norms that individuals adhere 
to, in turn providing for group success and stability. The physical and business work environment would feel safe and secure. The work experience would be one where individuals felt confident in the University's ability to provide financial stability and equitable policies, practices and pay.

Table XI: OSAS and 'PWI' IDEAL to IDEAL Domain Pattern ALL RESPONSES

\begin{tabular}{|l|c|c|c|c|}
\hline \multirow{2}{*}{$\begin{array}{c}\text { MAUT Place to } \\
\text { Work Pattern }\end{array}$} & \multicolumn{3}{|c|}{ OSAS IDEAL Domains - Most Frequently Occurring Pattern } \\
\cline { 2 - 5 } & $\begin{array}{c}\text { Control } \\
\text { Ideal }\end{array}$ & $\begin{array}{c}\text { Affect } \\
\text { Ideal }\end{array}$ & $\begin{array}{c}\text { Content } \\
\text { Ideal }\end{array}$ & $\begin{array}{c}\text { Meaning } \\
\text { Ideal }\end{array}$ \\
\hline C-S & C-S & C-S & C-S \\
$\begin{array}{l}\text { Index IDEAL } \\
\text { Security }\end{array}$ & Security & Security & Security \\
\hline
\end{tabular}

The pattern continuity across all respondents is significant and provides MU Extension with a substantive point of discussion and descriptive review. It should help yield an improved understanding of the workplace attributes that are important to their employees and would contribute to an optimal work environment for their respective workforce. In addition to day-today work environment basics like the set up of physical space and employee interaction, decision points for this specific University demographic should take into account the business processes associated with Extension and review them through the application of a workforce who prefers Security and ClosedSynchronous environments. Whether it is budget or strategic planning, communication plans, positional authority, curriculum, grant writing and research design, consensus building, or leadership responsibilities, this work group is 
inclined to have more productive and satisfying outcomes when their base needs around security and harmonious, yet structured, work interactions are specifically designed and implemented in a manner that plays to the strengths and $\mathrm{EB}$ preferences of the overall workplace.

\section{Discussion}

The intent of this dissertation was to identify shared or divergent qualities between environment behavior characteristics of the 'Place to Work' Index and the Organizational Systems Assessment Survey. The research examined the occurrence of statistically related attributes of the 'Place to Work' Index and the OSAS. Although outside the scope of this dissertation, both survey assessment tools were used in conjunction with other indexes to further EB work and environment studies, and are applicable for use with a multitude of workplace instruments.

The contributions are important to the field at this time for three main reasons. First, Environment and Behavior studies has an opportunity on the horizon to expand beyond what has traditionally been seen as a science that is tied heavily to the built environment and the interaction within it. The domain is primed to expand into an increasingly holistic environmental approach wherein all aspects of the human experience can be pulled into the research and into the science. The design, the build, the work, the processes, the environmental "norms", the psycho-social, and socio-economic indicators all play at once an increasingly complex and integrated role in the ongoing evolution of Environment 
and Behavior studies. This dissertation work contributes to the effort to expand on the base principles of EB and continues to formulate new application.

Second, as discussed previously, there are numerous surveys that are used in business settings to measure aspects of the workplace. The data are obtained in order to assist the employer in one of three general categories: 1) Culture and Leadership, 2) Products and Services and/or, 3) Competitiveness and Efficiencies. This dissertation provides an environment behavior tool for application in the workplace where currently, no Index exists. The tool can assist businesses in creating economies of scale by offering a blended approach to the three traditional data categories, in conjunction with the EB attributes. Efforts focused on the complement and/or contrast that respective workplace environments have in relationship to the thematic qualities of financially successful, employee-centric workplaces. The information derived from this study can assist business leaders in their decision making process as they look to create more befitting, deliberate work environment for their employees.

The third component of this dissertation's contribution is the opportunity to provide a combined tool that can be used for further research in the workplace. The 'Place to Work' Index and/or Organizational Systems Assessment Survey can be combined with other assessment tools to measure the relational perspective of multiple measurements. It can also be applied to various demographic components. For instance, a researcher who is interested in gender preferences in the workplace, could apply the Index or OSAS through the lens of 
gender and establish whether or not there is a gender bias preference on the Index or OSAS qualities. The tool can also be used by the academic and non-profit community to combine with other multi-disciplinary research methods to further pursue the theoretical links between the worker and workplace.

This research project also presented a unique opportunity to further dissect the characteristics of work environment preference and organizational regime. It further provides a "jumping off" point for additional research and refinement of the analysis and ideas presented in this document.

\section{Limitations of the Study}

The University of Missouri Extension provided a statistically significant pool of working adults. The survey was sent through University email to over 1,000 employees. During the three week period that the survey was open, 411 individuals participated. Although several reminders were sent to the participants, the number of overall respondents did not yield as large a sample as desired. A larger sample would have increased the reliability of the results and would have provided the ability to draw stronger conclusions about the preferences of the overall Extension population. The end result, however, provided a response rate that was sufficiently high producing an acceptable sample size on which to perform statistically significant analyses. The data sampling derived from a variety of employees in varying organizational settings, geographic locations, and positions that provided a unique opportunity to test the ACTUAL and IDEAL 
attributes of the PWI and OSAS. The strength of the sample was the diverse nature of the respondents and demographic level of detail available through the survey. However, even with detailed demographic responses and a pin-pointed comparison and contrast at the organization specific level, the disparities of IDEAL and ACTUAL were not significantly relevant.

\section{Conclusion}

When looking at the evolution of environment behavior studies it is possible to see a myriad of applications in the workplace, from the physical setting (e.g. lighting, temperature, layout, noise) to work processes (e.g. technology, work flow, decision making, process improvement) to social cues (e.g. teambuilding, hierarchy, cultural intelligence, workplace norms) and psychological components (e.g. autonomy, intrinsic value, stressors, motivators). EB influences every aspect of modern business. Sustainability in a constantly changing work world has become the holy grail of modern business. In order to survive and thrive, an organization must be profitable; recruiting and retaining productive, motivated talent is one of the keys to continued innovation and capital preservation. The findings of this research indicate that the 'Place to Work' Index and the Organizational System Assessment Survey are complimentary tools that can be applied in any type of work setting. In combination with one another they provide an encompassing view of the actual work experience of the employees who participate in the survey, and uniquely, they also provide a comparison view of the ideal work experience the respondents' prefer. The survey process not only 
tracks which of the attributes of highly successful, employee-centric businesses are most important to the respondent, but it also hones in on the organizational system presence and preference of the individuals completing the survey. This is not to say that a business cannot be profitable or have longevity if it fails to aspire to a better understand of the desired attributes of its workforce. Unfortunately, there are ample examples of numerous companies that have experienced substantial financial success in the midst of providing deplorable working conditions, unethical business dealings, or sub-par work experiences for the employee. This research however, is motivated by the opportunity to emphasize a win-win business proposition for both the company and the employees. When profitability stems from a work environment that is both preferred and motivating to the individual, the possibilities are limitless and the residual effects on society are significant. Employees flourish when the company's leaders help them focus on what matters most, not only at work but in all aspects of their lives - at home, in their communities, and in their pursuit of well-being. Organizations that create a level of comfort for the individual, emphasize the value of each person's authenticity, and encourage employees to freely choose to devote their energy to work and personal lives in a manner that is in sync with their deeply held values, manifest a business environment where the outcome is a workforce of committed people who drive toward achieving superior performance (Friedman \& Lobel, 2003). To this end, the 'Place to Work' Index was used in conjunction with the OSAS in pursuit of the qualities that provide for this class of workplace and work experience. 


\section{Future Research}

In summary, the main contribution of this research was the examination of numerous environment-behavior workplace attributes evident in Fortune 500 and 100 Best Place to Work Companies through employing the 'Place to Work' Index and a cross related understanding of the relationship between Organizational System and the Index for the purposes of establishing an easy-to-administer, multifaceted combined workplace assessment. The analysis of participant responses provided for the statistical extrapolation of correlated attributes, allowing for an organizational assessment of the Extension workforce as it relates to EB. The results of this study indicate that the two assessment tools used in conjunction with one another provide a comprehensive view of what individual's actually experience and prefer in their respective work environments.

Because this was the first time that the two tools were used together, a cross-industry application of this combined EB indicator should be explored through further research. One area of particular interest would be examining 'Place to Work' and OSAS employee preferences in other professions not related to higher education. Testing the combined tool in profit and not-for-profit businesses to see if patterns emerge differently would be a noteworthy exploration. Another area would be to apply the combined tool by generational demographics or through an examination of specific professions or industries. A third area would be 'Place to Work'/OSAS preferences by level of employee (e.g. executive, management, professional, front line, etc.) Lastly, the combined 
attributes could be examined for application within other organizational domains (e.g. family systems, team sports, academic relationships, diversity initiatives, etc).

A final possible avenue for future research would be to refine the statistical and mathematical algorithms that define both indices. The MAUT is a powerful tool most useful in this research as the primary algorithm for examining data systemically. While the current algorithm has been in practice for over 20 years, a more refined and robust approach than the binary-based algorithm should be explored. 


\section{BIBLIOGRAPHY}

Achor, S. (2011). The Happiness Advantage:The Seven Principles of Positive PsychologyThat Fuel Our Success and Performance at Work. United Kingdom: Virgin Publishing.

Adams, J. (1965). Inequity in Social Exchange. Advances in Experimental Social Psychology, 335-343.

Alderfer, C. (1969). An Empirical Test of a New Theory of Human Needs. Organizational Behavior and Human Performance, 142-175.

Alumni Harvard Business School. (1999, April). Retrieved October 2011, from Harvard Business School Bulletin:

http://www.alumni.hbs.edu/bulletin/1999/april/spirit3.html

Anchor, S. (2012). Positive Intelligence. Harvard Business Journal, 100-102.

Anderson, L. (2002). Benton MacKaye: Conservationist, Planner, and Creator of the Appalachian Trail . Baltimore: Johns Hopkins Univerity Press.

Barker, R. (1990). Recollections of the Midwest Psychological Field Station. Environment and Behavior, 503-513.

Bechtel, R. B. (1997). Environment and Behavior: An Introduction. Thousand Oaks: Sage.

Bootzin, R. L., Loftus, E.,Zajonc, R. \& Hall, E. (1983). Psychology Today: An Introduction. New York: Random House. Fifth Edition.

Bradberry, T. \& Greaves, J. (2009). Emotional Intelligence 2.0. San Diego: TalentSmart.

Bradford, D. L. \& Burke, W.W. (2005). Reinventing Organization Development: New Approach to Change in Organizations. San Francisco: Pfeiffer.

Burnes, B. (2004). Kurt Lewin and The Planned Approach to Change: A ReAppraisal. Journal of Management Studies, 977-1002.

Burnes, B. (2004). Managing Change:A Strategic Approach to Organisational Dynamics (4th ed). Upper Saddle River: Prentice Hall.

Carson, R. (1962). Silent Spring. Boston: Houghton Miffin. 
Cooke, B. (1999). Writing the Left out of Management Theory: The

Historiography of the Management of Change . Organization, 81-105.

Cornell University. (2011). Retrieved October 2011, from

http://www.ilr.cornell.edu: www.ilr.cornell.edu/LaborRelations

Covey, S. M., Covey, S. R., \& Merrill, R. R. (2006). The Speed of Trust. New York: Simon \& Schuster.

Covey, S. R. (1992). Principle-Centered Leadership. New York: Simon \& Schuster.

Covey, S. R. (2009). The 7 Habits of Highly Successful People. New York: Rosetta Books.

Cummings, T. G. (1989). Organization Development and Change (4th ed.). St

Paul: West Publishing.

Demerath, N.J. and Peterson, R. (1967) System Change and Conflict: A Reader on Contemporary Sociological Theory and the Debate over functionalism. New York: Free Press.

Department of Interior Design. (2010, October). Retrieved July 2012, from Washington State University: http://id.wsu.edu/2010/10/mccoy/

Department of Psychology. (2012, July). Retrieved July 2012, from University of Tennessee: http://psychology.utk.edu/people/sundstrom.html

Druker, P. F. (2002). The Effective Executive. New York: Harper Collins.

Dyck, J. (1997). Faith Under Test: Alternative Service During World War II in the U.S. and Canada . Moundridge: Gospel Publishers.

Earley, P. \& Masakowski, E. (2004). Cultural Intelligence. Harvard Business Review, 1-8.

Edwards, Ward and Newman, J. Robert (1982). Multiattribute Evaluation. London: Sage Publication, Inc.

Edwards, Ward (1997), "How to Use Multiattribute Utility Measurement for Social Decision-making," IEEE Transactions on Systems, Man, and Cybernetics, Vol. SMC7, No.5, May 1977.

French, W. (1982). The Emergence and Early History of Organization Development. Group Organizational Dynamics, 261-278. 
Gingerich, M. (1949). Service for Peace: A History of Mennonite Civilian Public Service. Goshen: Mennonite Central Committee.

Great Place To Work:Our Approach. (2010). Retrieved 2010-2011, from Great Place To Work Institute: http://greatplacetowork.com

Heil G., Bennis, W. \& Stephens,D.C., (2000). Douglas McGregor Revisited: Managing the Human Side of Enterprise. New York: John Wiley.

Herzberg, F. (1966). Work and the Nature of Man. Cleveland: World Publishing Co.

http://guides.library.cornell.edu/organizationalbehavior. (2011, September).

Retrieved September 2011, from Cornell University: http://www.ilr.cornell.edu

Imig, D. R. (1992). Operationalizing Paradigmatic Family Theory: The Family Regime Assessment Scale (FRAS). Family Science Review, 5(3), 217-234.

Institute For Organizational Excellence. (2010). Retrieved November 2010, from University of Texas at Austin: http://www.utexas.edu/research/cswr/survey

Kaplan, S. \& Kaplan, R. (1978). Humanscape:Environments for People. Belmont: Duxbury.

Kantor, D. \& Lehr, W. (1980). Inside the Family. San Francisco:Jossey-Bass.

Lewin, K. (1946).Action Research and Minority Problems. Journal of Social Issues, 34-36.

Locke, E. A. \& Latham, G.P. (1984). Goal Setting: A Motivational Technique That Works! Engelwood Cliffs: Prentice-Hall.

Locke, E. A.(1968). Toward a Theory of Task Motivation and Incentives. Organizational Behavior and Human Performance, 157-189.

Lundberg, C. (2000). Organizational Development as Facilitating the Surfacing and Modification of Social Rules. Research in Organizational Change and Development, 41-58.

Maslow Summary. (2011, July). Retrieved July 2011, from Sonoma State University: http://www.sonoma.edu/users/d/daniels/maslow_summary.html Maslow, A. (1970). Motivation and Personality (2nd ed.). New York: Harper \& Row. 
McGregor, D. (1957). The Human Side of Enterprise. Proceedings of the Fifth Anniversary Convocation of the School of Industrial Management. Boston: Massachusetts Institute of Technology.

Moore, G. T., Tuttle, D.P., Howell, S.C (1985). Environmental Design Research Directions: Process and Prospects. New York: Praeger.

Newstrom, J.W. \& Davis, K.A. (2007). Organizational Behavior: Human Behavior at Work. New York: McGraw-Hill.

Ore, A. (1835). The Philosophy of Manufactures. London: William Clowes \& Sons. Porteous, J. (1977). Environment and Behavior: Planning and Everyday Urban Life, Boston: Addison-Wesley.

Sommer, R. (1969). Personal Space: The Behavioral Basis of Design. Engelwood Cliffs: New Jersey.

Spector, P. E. (2008). Industrial and Organizational Behavior (5th ed). Hoboken: Wiley.

Spreitzer, G. \& Porath, C. (2012). Creating Sustainable Performance. Harvard Business Journal, 93-99.

Stewart-Pollack, J. \& Menconi, R. (2005). Designing for Privacy and Related Needs. New York: Fairchild Publications, Inc.

Tay, L. \& Diener, E. (2011). Needs and Subjective Well-Being Around the World. Journal of Personality and Social Psychology, 354-365.

The Drucker Institute. (2011). Retrieved August 2011, from The Drucker Institute Claremont Graduate University: http://www.druckerinstitute.com

Transcendentalism. (2011). Retrieved August 2011, from Websters Online Dictionary: http://www.websters-online-dictionary.org/definitions Vroom, V. (1964). Work and Motivation. New York: Jon Wiley \& Sons. Wartzman, R. (2012). What Would Drucker Do Now? New York: The McGraw Hill Companies.

White, L. (1967). The Historical Roots of Our Ecological Crisis. Science, 1-7. 
www.investinganswers.com. (2013, January). Retrieved 2013, from Investing Answers: http://www.investinganswers.com/financial-dictionary/businessescorporations/fortune-500-71

www.greatplacetowork.com. (2013, January). Retrieved January 2013, from Great Place To Work: http://www.greatplacetowork.com/best-companies/100best-companies-to-work-for 


\section{Appendix}

\section{Letter of Informed Consent}

Your participation in this research is voluntary and anonymous. You can stop at any time. You do not have to answer any questions you do not wish to answer. Refusal to take part in or withdrawing from this study will involve no penalty or loss of benefits you would receive otherwise. All publications and/or presentations resulting from the research will be reported in aggregate form only; no personally identifiable information will be collected. The University of Missouri's Institutional Review Board may review records related to this research study.

Your completion of the survey will be deemed as your consent to participate in the study.

Please contact the principal investigator, Dr. Ronn Phillips (Housing and Environmental Design Extension State Specialist), if you have questions or concerns about this research: Email: phillipsr@missouri.edu. If you have any questions, concerns, problems about your rights as a research participant or would like to offer input, please contact the University of Missouri Institutional Review Board ay 573.882 .9585 or by mail at 483 McReynolds, University of Missouri, Columbia, MO 65211.

I know how limited and valuable your time is. So, the instrument is designed to be completed by most participants in about 15- 20 minutes. I have completed mine. I hope you will complete yours as soon as possible.

Thank you in advance for your participation in this valuable effort to strengthen University of Missouri Extension. 


\section{Appendix}

\section{INITIAL CONTACT: Dr. Michael Ouart}

\section{IRB:10207311}

\section{Subject: "Your link to the Learning Organization Survey at University of Missouri Extension"}

Dear Colleagues:

I am inviting you to participate in the Learning Organization Survey that is being conducted by University of Missouri Extension and encouraging your participation in this important research undertaking.

A learning organization has a simple premise at its core: it is an organization that encourages its employees to more effectively collaborate and continue to learn in a climate of ever-increasing change, positioning the organization to become agile and versatile.

The survey is designed to gain the clearest picture of the structure and nature of the learning organization. A precise perspective of the system's components permits a learning organization to improve the dynamics among its parts - to effectively evolve. A people-oriented focus allows the learning organization to promote unambiguous and open communication yielding shared understanding and meaning, and ultimately leads to sharpened leadership skills, the capacity to think differently, and make faster and better decisions. Striving for the synergy only possible from group collaborations, the learning organization attempts to transcend accomplishments based on individual efforts.

This understanding stems from two important perspectives: (1) how individuals perceive the organization in its current condition (ACTUAL), and (2) how individuals would prefer to see the organization operate (IDEAL). Because of the importance of gaining a holistic understanding of the organization, the survey population includes all University Extension personnel, (i.e. administration, faculty, specialists, and staff).

The 15 - 20 minute survey can be accessed through SurveyMonkey at:

https://www.surveymonkey.com/s/LearningOrganizationSurveyUniversityOfMissouriExtension

Your participation in this research is voluntary and anonymous. You can stop at any time. You do not have to answer any questions you do not wish to answer. Refusal to take part in or withdrawing from this study will involve no penalty or loss of benefits you would receive otherwise. All publications and/or presentations resulting from the research will be reported in aggregate form only; no personally identifiable information will be collected. The University of Missouri's Institutional Review Board may review records related to this research study. 
Your completion of the survey will be deemed as your consent to participate in the study.

Please contact the principal investigator, Dr. Ronn Phillips (Housing and Environmental Design Extension State Specialist), if you have questions or concerns about this research: Email: phillipsr@missouri.edu. If you have any questions, concerns, problems about your rights as a research participant or would like to offer input, please contact the University of Missouri Institutional Review Board ay 573.882 .9585 or by mail at 483 McReynolds, University of Missouri, Columbia, MO 65211.

Thank you in advance for your participation in this valuable effort to strengthen University of Missouri Extension.

\section{FIRST FOLLOW-UP: Dr. Ronn Phillips}

\section{Subject: "Your link to the Learning Organization Survey at University of Missouri Extension"}

Dear Colleagues:

A few days ago, you were E-mailed an invitation to participate in the Learning Organization Survey in University of Missouri Extension. I am writing to you to remind you of the importance of your participation in this survey. As you know, this survey is designed to enhance our understanding of the structure of the organization in order to become more versatile and agile in a climate of ever-increasing change.

If you have already completed the survey, please accept my sincere thanks. If you have not completed the survey, I hope you will do so as soon as possible.

The E-mail with the specific survey site link should have arrived within the past few days from Dr. Michael Ouart with the header "Your link to the Learning Organization Survey at University of Missouri Extension." If, by chance, you accidently deleted or did not receive the E-mail, the survey site may be accessed at the following link:

\section{https://www.surveymonkey.com/s/LearningOrganizationSurveyUniversityOfMissouriExtension}

Your participation in this research is voluntary and anonymous. You can stop at any time. You do not have to answer any questions you do not wish to answer. Refusal to take part in or withdrawing from this study will involve no penalty or loss of benefits you would receive otherwise. All publications and/or presentations resulting from the research will be reported in aggregate form only; no personally identifiable information will be collected. The University of Missouri's Institutional Review Board may review records related to this research study.

Your completion of the survey will be deemed as your consent to participate in the study. 
Please contact the principal investigator, Dr. Ronn Phillips (Housing and Environmental Design Extension State Specialist), if you have questions or concerns about this research: Email: phillipsr@missouri.edu. If you have any questions, concerns, problems about your rights as a research participant or would like to offer input, please contact the University of Missouri Institutional Review Board ay 573.882 .9585 or by mail at 483 McReynolds, University of Missouri, Columbia, MO 65211.

I know how limited and valuable your time is. So, the instrument is designed to be completed by most participants in about 15- 20 minutes. I have completed mine. I hope you will complete yours as soon as possible.

Thank you in advance for your participation in this valuable effort to strengthen University of Missouri Extension.

\section{SECOND FOLLOW-UP: Dr. Ronn Phillips}

\section{Subject: "Your link to the Learning Organization Survey at University of Missouri Extension"}

Dear Colleagues:

A few weeks ago, you were E-mailed an invitation to participate in the Learning Organization Survey in University of Missouri Extension. I am writing to you to remind you of the importance of your participation in this survey. As you know, this survey is designed to enhance our understanding of the structure of the organization in order to become more versatile and agile in a climate of ever-increasing change.

If you have already completed the survey, please accept my sincere thanks. If you have not completed the survey, I hope you will do so as soon as possible.

The E-mail with the specific survey site link should have arrived within the past few weeks from Dr. Ronn Phillips, phillipsr@missouri.edu with the header "Your link to the Learning Organization Survey at University of Missouri Extension." If, by chance, you accidently deleted or did not receive the E-mail, the survey site may be accessed at the following link:

https://www.surveymonkey.com/s/LearningOrganizationSurveyUniversityOfMissouriExtension

Your participation in this research is voluntary and anonymous. You can stop at any time. You do not have to answer any questions you do not wish to answer. Refusal to take part in or withdrawing from this study will involve no penalty or loss of benefits you would receive otherwise. All publications and/or presentations resulting from the research will be reported in aggregate form only; no personally identifiable information will be collected. The University of Missouri's Institutional Review Board may review records related to this research study. 
Your completion of the survey will be deemed as your consent to participate in the study.

Please contact the principal investigator, Dr. Ronn Phillips (Housing and Environmental Design Extension State Specialist), if you have questions or concerns about this research: Email: phillipsr@missouri.edu. If you have any questions, concerns, problems about your rights as a research participant or would like to offer input, please contact the University of Missouri Institutional Review Board at 573.882 .9585 or by mail at 483 McReynolds, University of Missouri, Columbia, MO 65211.

I know how limited and valuable your time is. So, the instrument is designed to be completed by most participants in about 15 - 20 minutes. I hope you will complete the survey as soon as possible.

Thank you in advance for your participation in this valuable effort to strengthen University of Missouri Extension. 


\section{Appendix}

\section{Workplace Attributes Survey}

The survey items below are the substantive data collection components in hardcopy format. The final electronic survey will contain all necessary instructions for completing the survey. Upon approval of this survey, the electronic survey will be developed and resubmitted for final approval.

ASSIGN A VALUE OF 10 TO ONLY ONE ANSWER FOR THE (ACTUAL) CONDITION THAT BEST DESCRIBES YOUR OPINION. THEN, ASSIGN A VALUE FROM O TO 9 TO EACH OF THE REMAINING ANSWERS IN THE (ACTUAL) VALUE LIST COMPARING IT WITH THE ONE YOU IDENTIFIED AS BEST DESCRIBING YOUR OPINION. REPEAT THIS PROCEDURE, BUT FOR THE (IDEAL) CONDITION THIS TIME.

(1) What is the approach University of Missouri Extension most typically uses to achieve and accomplish what it wants (ACTUAL)? And, what approach would you prefer it uses to achieve and accomplish what it wants (IDEAL)?

\section{ACTUAL IDEAL VALUE VALUE}

\begin{tabular}{|l|l|l|}
\hline (a) Unstated agreements and just knowing what to do & & \\
\hline (b) Authority, rules, and discipline & & \\
\hline (c) Personal freedom, individual competence, and choice & & \\
\hline (d) Cooperation, discussion, and mutual agreement & & \\
\hline
\end{tabular}

(2) In what manner does University of Missouri Extension express its caring and support for each other (ACTUAL)? And, how would you prefer that it expresses its caring and support for each other (IDEAL)?

\begin{tabular}{|c|c|c|}
\hline & $\begin{array}{l}\text { ACUTAL } \\
\text { VALUE }\end{array}$ & $\begin{array}{l}\text { IDEAL } \\
\text { VALUE }\end{array}$ \\
\hline (a) Expressive, responsive, and given willingly & & \\
\hline (b) Private, formal, and regulated & & \\
\hline (c) Spontaneous, public, and enthusiastic & & \\
\hline $\begin{array}{l}\text { (d) Limited, reserved, and rarely expressed because we } \\
\text { know we care deeply for each other }\end{array}$ & & \\
\hline
\end{tabular}

(3) How would you describe the "essence" or identity of University of Missouri Extension (ACTUAL)? And, how would you prefer the "essence" or identity to be described (IDEAL)? 


\begin{tabular}{|c|c|c|}
\hline & $\begin{array}{l}\text { ACTUAL } \\
\text { VALUE }\end{array}$ & $\begin{array}{l}\text { IDEAL } \\
\text { VALUE }\end{array}$ \\
\hline (a) Impulsive, instinctive, and energetic & & \\
\hline (b) Traditional, stable, and consistent & & \\
\hline (c) Precise, exact, controlled, and harmonious & & \\
\hline (d) Practical, tolerant, and relevant & & \\
\hline
\end{tabular}

4) As University of Missouri Extension experiences the objective events and situations in life, how does it seek to understand those events (ACTUAL)? And, how would you prefer that it seeks to understand those events (IDEAL)?

\begin{tabular}{|l|l|l|}
\multicolumn{2}{|c|}{\begin{tabular}{l} 
ACTUAL \\
\multicolumn{1}{|c|}{ VALUE }
\end{tabular} VALUL } \\
\hline $\begin{array}{c}\text { (a) By being flexible, questioning, and challenging } \\
\text { (b) By relying on individual strengths, unique explanations, } \\
\text { and by being explorative }\end{array}$ & & \\
\hline $\begin{array}{c}\text { (c) By being methodical, conservative and by using time- } \\
\text { tested explanations }\end{array}$ & & \\
\hline (d) By being knowing, certain, wise, and assured & & \\
\hline
\end{tabular}

(5) What is University of Missouri Extension's most important characteristic (ACTUAL)? And, what would you prefer to be its most important characteristic (IDEAL)?

ACTUAL IDEAL

VALUE VALUE

\begin{tabular}{|l|l|l|}
\hline (a) Our understanding of the objective world around us & & \\
\hline (b) The identity of the organization, who we are and what & & \\
we stand for & & \\
\hline (c) The care and support that we give to each other & & \\
\hline (d) That we accomplish, achieve, and do what we want & & \\
\hline
\end{tabular}


(6) How important is each of the following workplace attributes to University of Missouri Extension (ACTUAL), and to you (IDEAL)?

$\begin{array}{ll}\text { ACTUAL } & \text { IDEAL } \\ \text { VALUE } & \text { VALUE }\end{array}$

\begin{tabular}{|l|l|l|}
\hline $\begin{array}{c}\text { (a) SECURITY: financial strength, secure and stable work } \\
\text { environment - both the physical (office/workplace) } \\
\text { and business environment (pay, policies, practices) }\end{array}$ & \\
\hline $\begin{array}{c}\text { (b) INTEGRITY: behaving with integrity, employees work } \\
\text { well together - they place faith and trust in each } \\
\text { other }\end{array}$ & \\
\hline $\begin{array}{c}\text { (c) RECIPROCITY: valuing the employer/employee } \\
\text { relationship -- both are equally important }\end{array}$ & \\
\hline $\begin{array}{c}\text { (d) CITIZENSHIP: dedicated to doing the right things in } \\
\text { organizational dealings, in the work environment, } \\
\text { and in the community }\end{array}$ & \\
\hline $\begin{array}{l}\text { (e) AUTHENTICY: employees get to be their true selves -- } \\
\text { empathy, solidarity and tolerance is shown to } \\
\text { everyone }\end{array}$ & \\
\hline
\end{tabular}

7) How important is each of the following environmental preferences to University of Missouri Extension (ACTUAL), and to you (IDEAL)?

ACTUAL IDEAL VALUE VALUE

(a) PHYSICAL FACILITY: layout, technology, equipment, well-constructed, well-maintained, adequate privacy, appropriate workspace(s)

(b) FURNITURE \& EQUIPMENT: congruent, ergonomic, comfortable, natural \& artificial lighting, comfortable ventilation

(c) CONTROL: workplace location \& options, collaboration space(s) or opportunities, accessibility to stimulation, lighting; ventilation \& privacy, personalization, adjacent activity centers

(d) CULTURE: facility fits image/brand, adaptable space(s), aesthetically pleasing, privacy fit, finishes $\&$ materials demonstrate image/brand, clear workspace(s)

(e) AMENITIES: adequate lounge space, vending areas and food service space(s), soothing space(s), operable windows, adequate storage, up-to-date equipment 
(8) How important to you (IDEAL) are the following workplace attributes?

IDEAL

VALUE

\begin{tabular}{|l|l|}
\hline (a) ACCESSIBLE SPACES: absence of physical barriers such as \\
stairs; presence of accessibility aids such as ramps and \\
handrails; and door widths, corridors, and elevators \\
that prevent easy movement.
\end{tabular}


FOR EACH OF THE SURVEY ITEMS BELOW, SELECT THE ONE RESPONSE THAT BEST DESCRIBES YOUR SITUATION.

(9) Which of the following responses best describes your job title - the area in which most of your work is undertaken? (Select one from below)

PULL DOWN MENU FOR ALPHABETIZED LIST OF JOB TITLES - SEE ADDENDUM B

(10) How long have you been employed with University of Missouri Extension? years (specify)

(11) In which Extension Region or Campus are you currently assigned? (Select one from below)
(a) Urban Region
(b) Northeast Region
(c) Northwest Region
(d) Southeast Region
(e) Southwest Region
(f) Columbia Campus
(g) Kansas City Campus
(h) Rolla Campus
(i) Saint Louis Campus
(j) Not Assigned to a Region or Campus

(12) The majority of your work assignments occur in which of the following University of Missouri Extension categories? (Select one from below)
(a) Administration/Management
(b) Agriculture \& Natural Resources
(c) Business Development
(d) Clerical/Support Staff
(e) Community Development
(f) Continuing Education
(g) Human Environmental Sciences
(h) 4-H/Youth

(13) Your Gender?

(a) Male

(b) Female 
(14) Your Age?

$$
\text { years (Specify) }
$$

(15) How long have you worked in your current office location?

$$
\text { years (Specify) }
$$

(16) During your employment with University of Missouri Extension, how many times have you relocated from one office facility to another?

number of times (Specify)

Thank you for your participation! 


\section{Appendix}

\section{ANALYSIS PLAN}

\section{THE SAMPLE SIRCA}

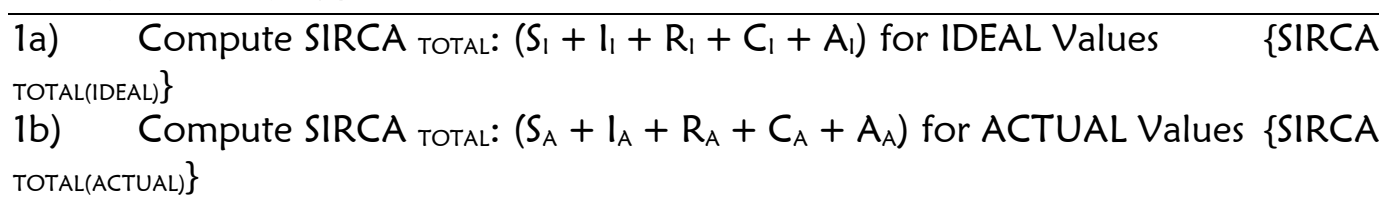

2a) Compute Proportional SIRCA (IDEAL) Values:

$$
\begin{aligned}
& S_{\%(I)}=S_{I} / \text { SIRCA tOtAL(IDEAL) } \\
& l_{\%(I)}=l_{1} / \text { SIRCA totaL(IDEAL) } \\
& \mathrm{R}_{\%(\mathrm{I})}=\mathrm{R}_{\mathrm{l}} / \text { SIRCA } \\
& C_{\%(I)}=C_{1} / \text { SIRCA TOTAL(IDEAL) } \\
& A_{\%(I)}=A_{l} / \text { SIRCA } A_{\text {TOtAL(IDEAL) }}
\end{aligned}
$$

2b) Compute Proportional SIRCA (Actual) Values:

$$
\begin{aligned}
& S_{\%(A)}=S_{A} / \text { SIRCA TOTAL(ACTUAL) } \\
& I_{\%(A) I}=I_{A} / \text { SIRCA } \\
& R_{\%(A)}=R_{A} / \text { SIRCA TOtAL(ACTUAL) } \\
& C_{\%(A)}=C_{A} / \text { SIRCA TOTAL(ACTUAL) } \\
& A_{\%(A)}=A_{A} / \text { SIRCA } A_{\text {TOTAL(ACTUAL) }}
\end{aligned}
$$

3a) Calculate Sample Mean Proportional SIRCA (IDEAL) Values:

$$
\begin{aligned}
& S_{\%(l)} \text { Mean } \\
& \text { I\%(I) Mean } \\
& \mathrm{R}_{\%(\mathrm{I})} \text { Mean } \\
& C_{\%(1)} \text { Mean } \\
& \mathrm{A}_{\%(1)} \text { Mean }
\end{aligned}
$$

3b) Calculate Sample Mean Proportional SIRCA (Actual) Values:

4a) Transform Proportional SIRCA (IDEAL) Values into Binary Coefficients:

$\mathrm{bS} \mathrm{F}_{(\mathrm{l})}=1$ if $\mathrm{S}_{\%(\mathrm{l})}>=\mathrm{S}_{\%(\mathrm{l})}$ Mean; else $\mathrm{b} \mathrm{S}_{\%(\mathrm{l})}=0$

$\mathrm{bl} \%(\mathrm{l})=1$ if $\mathrm{l}_{\%(\mathrm{l})}>=\mathrm{l}_{\%(\mathrm{I})}$ Mean; else $\mathrm{bl} \%(\mathrm{l})=0$

$b R_{\%(l)}=1$ if $R_{\%(l)}>=R_{\%(l)}$ Mean; else $b R_{\%(l)}=0$

$\mathrm{bC}_{\%(1)}=1$ if $\mathrm{C}_{\%(1)}>=\mathrm{C}_{\%(1)}$ Mean; else $\mathrm{b} \mathrm{C}_{\%(1)}=0$

$b A_{\%(l)}=1$ if $A_{\%(l)}>=A_{\%(1)}$ Mean; else $b A_{\%(l)}=0$

4b) Transform Proportional SIRCA (ACTUAL) Values into Binary Coefficients: $b S_{\%(A)}=1$ if $S_{\%(A)}>=S_{\%(A)}$ Mean; else $b S_{\%(A)}=0$

$\mathrm{bl} \%(\mathrm{~A})=1$ if $\mathrm{l}_{\%(\mathrm{~A})}>=\mathrm{l}_{\%(\mathrm{~A})}$ Mean; else $\mathrm{b} \mathrm{l}_{\%(\mathrm{~A})}=0$

$b R_{\%(A)}=1$ if $R_{\%(A)}>=R_{\%(A)}$ Mean; else $b R_{\%(A)}=0$

$b C_{\%(A)}=1$ if $C_{\%(A)}>=C_{\%(A)}$ Mean; else $b C_{\%(A)}=0$

$b A_{\%(A)}=1$ if $A_{\%(A)}>=A_{\%(A)}$ Mean; else $b A_{\%(A)}=0$ 
5a) Compute PATTERN (IDEAL) variable based on SIRCA (IDEAL) Binary Coefficients PATTERN $_{(\text {IDEAL })}=\left(\left(\mathrm{bS} \%_{(\mathrm{l})} * 16\right)+\left(\mathrm{bl}_{(\mathrm{l})} * 8\right)+\left(\mathrm{bR} \%_{(\mathrm{l})} * 4\right)+\left(\mathrm{bC} \%_{(\mathrm{l})} * 2\right)+\right.$ $(\mathrm{bA} \%(\mathrm{l}))$

5b) Compute PATTERN (ACTUAL) variable based on SIRCA (ACTUAL) Binary Coefficients PATTERN $_{(\text {ACTUAL }}=\left(\left(\mathrm{bS}_{(\mathrm{A})} * 16\right)+\left(\mathrm{bl}_{(\mathrm{A})} * 8\right)+\left(\mathrm{bR} \%_{(\mathrm{A})} * 4\right)+\left(\mathrm{bC} \%_{(\mathrm{A})} * 2\right)+\right.$ $(\mathrm{bA} \%(\mathrm{~A}))$

6a) Compute frequencies for PATTERN (IDEAL)

6b) Compute frequencies for PATTERN (ACTUAL)

7) Compute DISCREPANCIES between (IDEAL) and (ACTUAL) SIRCA components:

$S_{\text {DISC }}=S_{\%(I D E A L)}-S_{\%(A C T U A L)}$

$I_{\text {DISC }}=I_{\%(I D E A L)}=I_{\%(A C T U A L)}$

$\mathrm{R}_{\text {DISC }}=\mathrm{R}_{\%(\text { IDEAL) }}=\mathrm{R}_{\%(A C T U A L)}$

$C_{\text {DISC }}=C_{\%(\text { IDEAL })}=C_{\%(A C T U A L)}$

$A_{D I S C}=A_{\%(I D E A L)}=A_{\%(A C T U A L)}$

8) Compute frequencies for SIRCA DISCREPANCY (SAMPLE) components

SDISC

IDISC

R DISC

$C_{\text {DISC }}$

ADISC

9) Select Cases by GENDER and Compute frequencies for SIRCA DISCREPANCY components

SDISC

IDISC

$\mathrm{R}_{\text {DISC }}$

$C_{\text {DISC }}$

ADISC

10) Select Cases by AGE and Compute frequencies for SIRCA DISCREPANCY components

SDISC

IDISC

R DISC

$C_{\text {DISC }}$

A DISC

11) Select Cases by EMPLOYMENT STATUS and Compute frequencies for SIRCA DISCREPANCY components

SDISC

IDISC

$R_{D I S C}$

CDISC

ADISC 
12) Select Cases by EMPLOYMENT LENGTH and Compute frequencies for SIRCA DISCREPANCY components

SDISC

$\mathrm{I}_{\text {DISC }}$

$\mathrm{R}_{\text {DISC }}$

$C_{\text {DISC }}$

A DISC

13) Select Cases by COMPANY UNIT and Compute frequencies for SIRCA DISCREPANCY components

SDISC

$\mathrm{I}_{\text {DISC }}$

R DISC

CDISC

ADISC

\section{OSAS}

14a) Compute OSAS total: $\left(C_{1}+O_{1}+R_{1}+S_{1}\right)$ for IDEAL Values $\{$ OSAS total(IDEAL)\}

14b) Compute OSAS total: $\left(C_{A}+O_{A}+R_{A}+S_{A}\right)$ for ACTUAL Values \{OSAS total(ACtual)\}

15a) Compute Proportional OSAS (IDEAL) Values: $\quad C_{\%(I)}=C_{1} /$ OSAS tOTAL(IDEAL)

$O_{\%(I)}=O_{1} /$ OSAS TOTAL(IDEAL)

$\mathrm{R}_{\%(I)}=\mathrm{R}_{\mathrm{l}} /$ OSAS TOTAL(IDEAL)

15b) Compute Proportional OSAS (actual) Values:

$S_{\%(I)}=S_{1} /$ OSAS TOTAL(IDEAL)

$C_{\%(A)}=S_{A} /$ OSAS tOtal(ACtUAL)

$O_{\%(A) I}=I_{A} /$ OSAS TOTAL(ACTUAL)

$\mathrm{R}_{\%(A)}=\mathrm{R}_{\mathrm{A}} /$ OSAS TOTALACTUAL)

$S_{\%(A)}=C_{A} /$ OSAS TOTAL(ACTUAL)

16a) Calculate Sample Mean Proportional OSAS (IDEAL) Values: $\quad C_{\%(I)}$ Mean

O\%(l) Mean

$\mathrm{R}_{\%(1)}$ Mean

$S_{\%(1)}$ Mean

16b) Calculate Sample Mean Proportional OSAS (Actual) Values: $\quad C_{\%(A)}$ Mean

$\mathrm{O}_{\%(A)}$ Mean

$\mathrm{R}_{\%(\mathrm{~A})}$ Mean

$S_{\%(A)}$ Mean

17a) Transform Proportional OSAS (IDEAL) Values into Binary Coefficients:

$\mathrm{bC}_{\%(1)}=1$ if $\mathrm{C}_{\%(1)}>=\mathrm{C}_{\%(\text { (I) }}$ Mean; else $\mathrm{b} \mathrm{C}_{\%(1)}=0$

$\mathrm{bO}_{\%(l)}=1$ if $\mathrm{O}_{\%(l)}>=\mathrm{O}_{\%(l)}$ Mean; else $\mathrm{bO}_{\%(l)}=0$

$b R_{\%(l)}=1$ if $R_{\%(l)}>=R_{\%(l)}$ Mean; else $b R_{\%(l)}=0$

$b S_{\%(1)}=1$ if $S_{\%(1)}>=S_{\%(1)}$ Mean; else $b S_{\%(1)}=0$

17b) Transform Proportional OSAS (ACTuAL) Values into Binary Coefficients: $b C_{\%(A)}=1$ if $C_{\%(A)}>=C_{\%(A)}$ Mean; else $b C_{\%(A)}=0$ 
$\mathrm{bO}_{\%(\mathrm{~A})}=1$ if $\mathrm{O}_{\%(\mathrm{~A})}>=\mathrm{O}_{\%(\mathrm{~A})}$ Mean; else $\mathrm{bO} \%(\mathrm{~A})=0$

$b R_{\%(A)}=1$ if $R_{\%(A)}>=R_{\%(A)}$ Mean; else $b R_{\%(A)}=0$

$b S_{\%(A)}=1$ if $S_{\%(A)}>=S_{\%(A)}$ Mean; else $b S_{\%(A)}=0$

18a) Compute PATTERN (IDEAL) variable based on OSAS (IDEAL) Binary Coefficients

PATTERN $_{(\text {IDEAL })}=\left(\left(\mathrm{bC} \%_{(\mathrm{l})} * 8\right)+\left(\mathrm{bO} \%_{(\mathrm{I})} * 4\right)+\left(\mathrm{bR} \%_{(\mathrm{I})} * 2\right)+\left(\mathrm{bS} \%_{(\mathrm{I})}\right)\right)$

18b) Compute PATTERN (ACTUAL) variable based on OSAS (ACTUAL) Binary Coefficients

PATTERN $_{(\text {ACTUAL })}=\left(\left(\mathrm{bC} \%_{(A)} * 8\right)+\left(\mathrm{bO} \%_{(A)} * 4\right)+\left(\mathrm{bR} \%_{(\mathrm{A})} * 2\right)+\left(\mathrm{bS} \%_{(\mathrm{A})}\right)\right)$

19a) Compute frequencies for PATTERN (IDEAL)

19b) Compute frequencies for PATTERN (ACTUAL)

20) Compute DISCREPANCIES between (IDEAL) and (ACTUAL) OSAS components:

$C_{\text {DISC }}=C_{\%(\text { IDEAL) }}-C_{\%(A C T U A L)}$

$\mathrm{O}_{\text {DISC }}=\mathrm{O}_{\%(\text { IDEAL })}=\mathrm{O}_{\%(\mathrm{ACTUAL})}$

$R_{\text {DISC }}=R_{\%(I D E A L)}=R_{\%(A C T U A L)}$

$S_{\text {DISC }}=S_{\%(\text { IDEAL })}=S_{\%(A C T U A L)}$

21) Compute frequencies for OSAS DISCREPANCY (SAMPLE) components

CDISC

ODISC

$\mathrm{R}_{\text {DISC }}$

SDISC

22) Select Cases by GENDER and Compute frequencies for OSAS DISCREPANCY components

$C_{\text {DISC }}$

ODISC

RDISC

SDISC

23) Select Cases by AGE and Compute frequencies for OSAS DISCREPANCY components

$C_{\text {DISC }}$

ODISC

RDISC

SDISC

24) Select Cases by EMPLOYMENT STATUS and Compute frequencies for OSAS DISCREPANCY components

$C_{\text {DISC }}$

ODISC

RDISC

SDISC

25) Select Cases by EMPLOYMENT LENGTH and Compute frequencies for OSAS DISCREPANCY components 
CDISC

ODISC

$R_{\text {DISC }}$

$S_{\text {DISC }}$

26) Select Cases by COMPANY UNIT and Compute frequencies for OSAS DISCREPANCY components

$C_{\text {DISC }}$

ODISC

$R_{\text {DISC }}$

SDISC 


\section{Appendix}

\section{Additional Data Analysis}

SIC Pattern AGE- ACTUAL

\begin{tabular}{|l|c|c|c|c|}
\hline \multirow{2}{*}{ MAUT Pattern ACTUAL } & \multicolumn{4}{|c|}{ Age Quartile } \\
\cline { 2 - 5 } & $\begin{array}{c}\text { 1st }^{\text {st }} \\
\text { (to age 41) }\end{array}$ & $\begin{array}{c}2^{\text {Quartile }} \\
\text { (to age 53) }\end{array}$ & $\begin{array}{c}3^{\text {rd }} \text { Quartile } \\
\text { (to age 59) }\end{array}$ & $\begin{array}{c}4^{\text {th }} \text { Quartile } \\
\text { (to age 79) }\end{array}$ \\
\hline Citizenship & 15 & 15 & 7 & 9 \\
Integrity & 13 & 14 & 14 & 14 \\
Integrity and Citizenship & 11 & 12 & 16 & 13 \\
Security & 8 & 9 & 6 & 16 \\
Security and Citizenship & 5 & 8 & 12 & 1 \\
Security and Integrity & 16 & 13 & 9 & 8 \\
\hline
\end{tabular}

SIC Pattern AGE- IDEAL

\begin{tabular}{|l|c|c|c|c|}
\hline \multirow{2}{*}{ MAUT Pattern IDEAL } & \multicolumn{4}{|c|}{ Age Quartile } \\
\cline { 2 - 5 } & $\begin{array}{c}\text { 1st }^{\text {st }} \\
\text { (to age 41) }\end{array}$ & $\begin{array}{c}\text { Quartile }_{\text {Qua }} \\
\text { (to age 53) }\end{array}$ & $\begin{array}{c}\text { 3rd Quartile } \\
\text { (to age 59) }\end{array}$ & $\begin{array}{c}4^{\text {th }} \text { Quartile } \\
\text { (to age 79) }\end{array}$ \\
\hline Citizenship & 10 & 9 & 18 & 15 \\
Integrity & 7 & 12 & 13 & 11 \\
Integrity and Citizenship & 13 & 10 & 6 & 9 \\
Security & 26 & 20 & 17 & 10 \\
Security and Citizenship & 8 & 10 & 7 & 7 \\
Security and Integrity & 7 & 8 & 8 & 9 \\
\hline
\end{tabular}

\section{SIC Pattern GENDER- ACTUAL}

\begin{tabular}{|l|c|c|}
\hline \multirow{2}{*}{ MAUT Pattern ACTUAL } & \multicolumn{2}{|c|}{ GENDER } \\
\cline { 2 - 3 } & Male & Female \\
\hline & 18 & 38 \\
Citizenship & 24 & 40 \\
Integrity & 14 & 41 \\
Integrity and Citizenship & 19 & 31 \\
Security & 8 & 20 \\
Security and Citizenship & 21 & 33 \\
Security and Integrity & & \\
\hline
\end{tabular}


SIC Pattern CENDER- IDEAL

\begin{tabular}{|l|c|c|}
\hline \multirow{2}{*}{ MAUT Pattern IDEAL } & \multicolumn{2}{|c|}{ GENDER } \\
\cline { 2 - 3 } & Male & Female \\
\hline & 15 & 41 \\
Citizenship & 16 & 39 \\
Integrity & 21 & 21 \\
Integrity and Citizenship & 30 & 56 \\
Security & 12 & 27 \\
Security and Citizenship & 13 & 23 \\
Security and Integrity & \\
\hline
\end{tabular}

SIC Pattern TENURE- ACTUAL

\begin{tabular}{|l|c|c|c|c|}
\hline \multirow{2}{*}{ MAUT Pattern ACTUAL } & \multicolumn{4}{|c|}{ Tenure Quartile } \\
\cline { 2 - 5 } & $\begin{array}{c}\text { 1st Quartile } \\
\text { (to 5 years) }\end{array}$ & $\begin{array}{c}2^{\text {nd }} \text { Quartile } \\
\text { (to 11 years) }\end{array}$ & $\begin{array}{c}3^{\text {rd }} \text { Quartile } \\
\text { (to 20 years) }\end{array}$ & $\begin{array}{c}4^{\text {th }} \text { Quartile } \\
\text { (to 49 years) }\end{array}$ \\
\hline Citizenship & & & & \\
Integrity & 20 & 11 & 13 & 7 \\
Integrity and Citizenship & 15 & 9 & 11 & 19 \\
Security & 15 & 10 & 17 & 11 \\
Security and Citizenship & 11 & 8 & 13 & 12 \\
Security and Integrity & 9 & 3 & 5 & 7 \\
\hline
\end{tabular}

SIC Pattern TENURE- IDEAL

\begin{tabular}{|l|c|c|c|c|}
\hline \multirow{2}{*}{ MAUT Pattern IDEAL } & \multicolumn{4}{|c|}{ Tenure Quartile } \\
\cline { 2 - 5 } & $\begin{array}{c}1_{\text {st }}^{\text {Quartile }} \\
\text { (to 5 years) }\end{array}$ & $\begin{array}{c}2^{\text {nd }} \text { Quartile } \\
\text { (to 11 years) }\end{array}$ & $\begin{array}{c}3^{\text {rd }} \text { Quartile } \\
\text { (to 20 years) }\end{array}$ & $\begin{array}{c}4^{\text {th }} \text { Quartile } \\
\text { (to 49 years) }\end{array}$ \\
\hline Citizenship & 19 & 9 & 9 & 11 \\
Integrity & 14 & 7 & 12 & 18 \\
Integrity and Citizenship & 12 & 5 & 10 & 7 \\
Security & 28 & 13 & 19 & 14 \\
Security and Citizenship & 14 & 7 & 8 & 6 \\
Security and Integrity & 10 & 6 & 6 & 10 \\
\hline
\end{tabular}


SIC Pattern REGION- ACTUAL

\begin{tabular}{|l|c|}
\hline MAUT Pattern ACTUAL & All Regions Combined \\
\hline & \\
Citizenship & 54 \\
Integrity & 63 \\
Integrity and Citizenship & 55 \\
Security & 50 \\
Security and Citizenship & 27 \\
Security and Integrity & 53 \\
\hline
\end{tabular}

SIC Pattern REGION- IDEAL

\begin{tabular}{|l|c|}
\hline MAUT Pattern IDEAL & All Regions Combined \\
\hline Citizenship & 55 \\
Integrity & 53 \\
Integrity and Citizenship & 41 \\
Security & 83 \\
Security and Citizenship & 39 \\
Security and Integrity & 38 \\
\hline
\end{tabular}

SIC Pattern DISCIPLINE- ACTUAL

\begin{tabular}{|l|c|c|c|c|c|c|c|c|}
\hline \multirow{2}{*}{$\begin{array}{l}\text { Mattern } \\
\text { ACTUAL }\end{array}$} & \multicolumn{9}{|c|}{ Discipline } \\
\cline { 2 - 10 } & $\begin{array}{c}\text { Admin } \\
\text { Mgt }\end{array}$ & $\begin{array}{c}\text { Ag \& } \\
\text { Nat } \\
\text { Resources }\end{array}$ & $\begin{array}{c}\text { Clerical } \\
\text { Bus } \\
\text { Dev }\end{array}$ & $\begin{array}{c}\text { Comm } \\
\text { Dev } \\
\text { Support }\end{array}$ & $\begin{array}{c}\text { Cont } \\
\text { Ed }\end{array}$ & HES & $\begin{array}{c}4-\mathrm{H} / \\
\text { Youth }\end{array}$ \\
\hline No Pattern & 0 & 3 & 1 & 2 & 3 & 4 & 5 & 1 \\
\hline Citizenship & 7 & 10 & 6 & 7 & 5 & 3 & 11 & 7 \\
\hline Integrity & 8 & 11 & 5 & 5 & 3 & 1 & 21 & 9 \\
\hline $\begin{array}{l}\text { Integrity and } \\
\text { Citizenship }\end{array}$ & 10 & 8 & 8 & 0 & 3 & 2 & 14 & 9 \\
\hline Security & 5 & 8 & 3 & 1 & 7 & 1 & 13 & 9 \\
\hline $\begin{array}{l}\text { Security and } \\
\text { Citizenship }\end{array}$ & 2 & 5 & 0 & 1 & 3 & 3 & 11 & 2 \\
\hline $\begin{array}{l}\text { Security and } \\
\text { Integrity }\end{array}$ & 7 & 8 & 3 & 2 & 3 & 7 & 14 & 9 \\
\hline
\end{tabular}


$\underline{\text { SIC Pattern DISCIPLINE- IDEAL }}$

\begin{tabular}{|l|c|c|c|c|c|c|c|c|}
\hline \multirow{2}{*}{$\begin{array}{l}\text { Mattern } \\
\text { IDEAL }\end{array}$} & \multicolumn{9}{|c|}{ Discipline } \\
\cline { 2 - 10 } & $\begin{array}{c}\text { Admin } \\
\text { Mgt }\end{array}$ & $\begin{array}{c}\text { Ag \&Nat } \\
\text { Resources }\end{array}$ & $\begin{array}{c}\text { Clerical } \\
\text { Bus } \\
\text { Dev }\end{array}$ & $\begin{array}{c}\text { Comm } \\
\text { Support }\end{array}$ & $\begin{array}{c}\text { Cont } \\
\text { Ed }\end{array}$ & HES & $\begin{array}{c}4-\mathrm{H} / \\
\text { Youth }\end{array}$ \\
\hline No Pattern & 1 & 2 & 0 & 2 & 2 & 1 & 5 & 1 \\
\hline Citizenship & 13 & 5 & 7 & 2 & 3 & 4 & 13 & 7 \\
\hline Integrity & 9 & 9 & 6 & 4 & 2 & 0 & 15 & 8 \\
\hline $\begin{array}{l}\text { Integrity and } \\
\text { Citizenship }\end{array}$ & 3 & 11 & 2 & 2 & 7 & 4 & 6 & 5 \\
\hline Security & 9 & 12 & 6 & 1 & 8 & 7 & 27 & 12 \\
\hline $\begin{array}{l}\text { Security and } \\
\text { Citizenship }\end{array}$ & 2 & 8 & 3 & 3 & 3 & 2 & 14 & 4 \\
\hline $\begin{array}{l}\text { Security and } \\
\text { Integrity }\end{array}$ & 2 & 6 & 2 & 3 & 2 & 3 & 9 & 9 \\
\hline
\end{tabular}

OSAS Domain Pattern ALL RESPONSES- ACTUAL and IDEAL

\begin{tabular}{|c|c|c|c|c|c|c|c|c|}
\hline \multirow{2}{*}{$\begin{array}{l}\text { MAUT Pattern } \\
\text { ACTUAL and } \\
\text { IDEAL }\end{array}$} & \multicolumn{8}{|c|}{ OSAS Domains by Overall Sample $(n=411)$} \\
\hline & $\begin{array}{l}\text { Control } \\
\text { Actual }\end{array}$ & $\begin{array}{c}\text { Control } \\
\text { Ideal }\end{array}$ & $\begin{array}{l}\text { Affect } \\
\text { Actual }\end{array}$ & $\begin{array}{l}\text { Affect } \\
\text { Ideal }\end{array}$ & $\begin{array}{l}\text { Content } \\
\text { Actual }\end{array}$ & $\begin{array}{l}\text { Content } \\
\text { Ideal }\end{array}$ & $\begin{array}{l}\text { Meaning } \\
\text { Actual }\end{array}$ & $\begin{array}{c}\text { Meaning } \\
\text { Ideal }\end{array}$ \\
\hline $\begin{array}{l}\text { Most Frequent } \\
\text { Pattern } \\
\text { No Pattern }\end{array}$ & $\begin{array}{c}\text { O-R-S } \\
158\end{array}$ & C-S & O-R & O-R & 143 & R-S & $\begin{array}{l}\text { O-R-S } \\
\& \text { C-O- } \\
\text { R-S } \\
\quad 149\end{array}$ & C-S \\
\hline
\end{tabular}


OSAS MEANING Pattern GENDER- ACTUAL (MALE)

\begin{tabular}{|l|c|c|c|c|}
\cline { 1 - 3 } MAUT Pattern ACTUAL & \multicolumn{5}{|c|}{$\begin{array}{c}\text { Control } \\
\text { Male }\end{array}$} & $\begin{array}{c}\text { Affect } \\
\text { Male }\end{array}$ & $\begin{array}{c}\text { Content } \\
\text { Male }\end{array}$ & $\begin{array}{c}\text { Meaning } \\
\text { Male }\end{array}$ \\
\hline & & & & \\
\hline Synchronous & 7 & 13 & 9 & 2 \\
\hline Random & 5 & 2 & 6 & 5 \\
\hline Random-Synchronous & 3 & 4 & 4 & 2 \\
\hline Open & 7 & 8 & 10 & 5 \\
\hline Open-Synchronous & 1 & 2 & 4 & 4 \\
\hline Open-Random & 10 & 15 & 10 & 9 \\
\hline Open-Random-Synch & 12 & 1 & 8 & 7 \\
\hline Closed & 7 & 11 & 5 & 7 \\
\hline Closed-Synchronous & 7 & 5 & 4 & 5 \\
\hline Closed-Random & 1 & 1 & 2 & 3 \\
\hline Closed-Random-Synch & 3 & 7 & 6 & 3 \\
\hline Closed-Open & 2 & 2 & 1 & 5 \\
\hline Closed-Open-Synch & 3 & 1 & 8 & 4 \\
\hline Closed-Open-Random & 3 & 5 & 3 & 9 \\
\hline Closed-Open-Ran-Synch & 5 & 5 & 4 & 12 \\
\hline
\end{tabular}

OSAS MEANING Pattern GENDER- ACTUAL (FEMALE)

\begin{tabular}{|l|c|c|c|c|}
\hline \multirow{2}{*}{ MAUT Pattern ACTUAL } & \multicolumn{5}{|c|}{$\begin{array}{c}\text { Control } \\
\text { Female }\end{array}$} & $\begin{array}{c}\text { Affect } \\
\text { Female }\end{array}$ & $\begin{array}{c}\text { Content } \\
\text { Female }\end{array}$ & $\begin{array}{c}\text { Meaning } \\
\text { Female }\end{array}$ \\
\cline { 2 - 5 } & & & & \\
\hline Synchronous & 8 & 15 & 10 & 7 \\
\hline Random & 9 & 10 & 26 & 11 \\
\hline Random-Synchronous & 8 & 6 & 19 & 5 \\
\hline Open & 11 & 7 & 14 & 13 \\
\hline Open-Synchronous & 1 & 10 & 8 & 13 \\
\hline Open-Random & 21 & 30 & 11 & 12 \\
\hline Open-Random-Synch & 20 & 5 & 9 & 19 \\
\hline Closed & 16 & 16 & 5 & 9 \\
\hline Closed-Synchronous & 12 & 20 & 4 & 17 \\
\hline Closed-Random & 3 & 15 & 4 & 6 \\
\hline Closed-Random-Synch & 8 & 10 & 3 & 10 \\
\hline Closed-Open & 5 & 9 & 16 & 6 \\
\hline Closed-Open-Synch & 7 & 18 & 17 & 6 \\
\hline Closed-Open-Random & 10 & 10 & 7 & 4 \\
\hline Closed-Open-Ran-Synch & 17 & 9 & 3 & 13 \\
\hline
\end{tabular}


OSAS MEANING Pattern GENDER- IDEAL (MALE)

\begin{tabular}{|l|c|c|c|c|}
\hline \multirow{2}{*}{ MAUT Pattern IDEAL } & \multicolumn{5}{|c|}{$\begin{array}{c}\text { Control } \\
\text { Male }\end{array}$} & $\begin{array}{c}\text { Affect } \\
\text { Male }\end{array}$ & $\begin{array}{c}\text { Content } \\
\text { Male }\end{array}$ & $\begin{array}{c}\text { Meaning } \\
\text { Male }\end{array}$ \\
\hline & & & & \\
\hline Synchronous & 8 & 12 & 9 & 8 \\
\hline Random & 2 & 2 & 13 & 7 \\
\hline Random-Synchronous & 5 & 6 & 5 & 3 \\
\hline Open & 0 & 3 & 10 & 2 \\
\hline Open-Synchronous & 2 & 3 & 7 & 3 \\
\hline Open-Random & 11 & 13 & 12 & 8 \\
\hline Open-Random-Synch & 16 & 6 & 3 & 11 \\
\hline Closed & 4 & 5 & 3 & 6 \\
\hline Closed-Synchronous & 7 & 18 & 13 & 10 \\
\hline Closed-Random & 2 & 4 & 3 & 3 \\
\hline Closed-Random-Synch & 5 & 6 & 6 & 3 \\
\hline Closed-Open & 5 & 4 & 5 & 4 \\
\hline Closed-Open-Synch & 0 & 1 & 6 & 11 \\
\hline Closed-Open-Random & 8 & 6 & 2 & 7 \\
\hline Closed-Open-Ran-Synch & 5 & 5 & 0 & 10 \\
\hline
\end{tabular}

\section{OSAS MEANING Pattern GENDER- IDEAL (FEMALE)}

\begin{tabular}{|l|c|c|c|c|}
\hline \multirow{2}{*}{ MAUT Pattern IDEAL } & \multicolumn{5}{|c|}{$\begin{array}{c}\text { Control } \\
\text { Female }\end{array}$} & $\begin{array}{c}\text { Affect } \\
\text { Female }\end{array}$ & $\begin{array}{c}\text { Content } \\
\text { Female }\end{array}$ & $\begin{array}{c}\text { Meaning } \\
\text { Female }\end{array}$ \\
\cline { 2 - 5 } Synchronous & 7 & 8 & 13 & 28 \\
\hline Random & 1 & 6 & 13 & 9 \\
\hline Random-Synchronous & 4 & 5 & 29 & 6 \\
\hline Open & 3 & 8 & 16 & 9 \\
\hline Open-Synchronous & 2 & 6 & 12 & 2 \\
\hline Open-Random & 20 & 34 & 15 & 16 \\
\hline Open-Random-Synch & 13 & 6 & 8 & 9 \\
\hline Closed & 19 & 11 & 5 & 15 \\
\hline Closed-Synchronous & 31 & 28 & 16 & 33 \\
\hline Closed-Random & 2 & 9 & 13 & 3 \\
\hline Closed-Random-Synch & 11 & 11 & 25 & 6 \\
\hline Closed-Open & 4 & 15 & 12 & 3 \\
\hline Closed-Open-Synch & 8 & 7 & 5 & 3 \\
\hline Closed-Open-Random & 22 & 17 & 4 & 10 \\
\hline Closed-Open-Ran-Synch & 14 & 6 & 2 & 8 \\
\hline
\end{tabular}


OSAS Pattern TENURE - ACTUAL

\begin{tabular}{|l|c|c|c|c|}
\hline $\begin{array}{c}\text { MAUT Pattern } \\
\text { ACTUAL } \\
\text { Tenure Quartiles }\end{array}$ & $\begin{array}{c}\text { Control } \\
\text { Actual }\end{array}$ & $\begin{array}{c}\text { Affect } \\
\text { Actual }\end{array}$ & $\begin{array}{c}\text { Content } \\
\text { Actual }\end{array}$ & $\begin{array}{c}\text { Meaning } \\
\text { Actual }\end{array}$ \\
\hline 25 th (up to 5 years) & O-R & O-R & S & O-R-S \\
$50^{\text {th }}$ (up to 11 years) & O-R-S & O-R & R-S & O-R \\
$75^{\text {th }}$ (up to 20 years) & C & C & R & C-O-R-S \\
Above 20 years & O-R-S & C & O & C-S \\
\hline
\end{tabular}

OSAS Pattern TENURE - IDEAL

\begin{tabular}{|l|c|c|c|c|}
\hline $\begin{array}{c}\text { MAUT Pattern } \\
\text { ACTUAL } \\
\text { Tenure Quartiles }\end{array}$ & $\begin{array}{c}\text { Control } \\
\text { Ideal }\end{array}$ & $\begin{array}{c}\text { Affect } \\
\text { Ideal }\end{array}$ & $\begin{array}{c}\text { Content } \\
\text { Ideal }\end{array}$ & $\begin{array}{c}\text { Meaning } \\
\text { Ideal }\end{array}$ \\
\hline 25 th (up to 5 years) & $\begin{array}{c}\text { C-S \& } \\
\text { C-O-R }\end{array}$ & C-S & R-S & C-S \\
$50^{\text {th }}$ (up to 11 years) & C-S & C-S & R-S & S \\
$75^{\text {th }}$ (up to 20 years) & $\begin{array}{c}\text { O-R-S \& } \\
\text { C-S } \\
\text { Above } 20 \text { years }\end{array}$ & O-R & C-S & O-R \\
O-R & C-O & C-S \\
\hline
\end{tabular}

OSAS Pattern REGION - ACTUAL and IDEAL

\begin{tabular}{|l|c|c|c|c|c|c|c|c|}
\hline \multirow{2}{*}{ MAUT Pattern } & \multicolumn{7}{|c|}{ OSAS Domains - Most Frequently Occurring Pattern } \\
\cline { 2 - 8 } & $\begin{array}{c}\text { Control } \\
\text { Actual }\end{array}$ & $\begin{array}{c}\text { Control } \\
\text { Ideal }\end{array}$ & $\begin{array}{c}\text { Affect } \\
\text { Actual }\end{array}$ & $\begin{array}{c}\text { Affect } \\
\text { Ideal }\end{array}$ & $\begin{array}{c}\text { Content } \\
\text { Actual }\end{array}$ & $\begin{array}{c}\text { Content } \\
\text { Ideal }\end{array}$ & $\begin{array}{c}\text { Meaning } \\
\text { Actual }\end{array}$ & $\begin{array}{c}\text { Meaning } \\
\text { Ideal }\end{array}$ \\
\hline $\begin{array}{l}\text { All Regions } \\
\text { Combined }\end{array}$ & O-R-S & C-S & O-R & O-R & R & C-R-S & C-O-R-S & C-S \\
$\begin{array}{l}\text { Overall No } \\
\text { Pattern }\end{array}$ & 92 & 83 & 91 & 56 & 92 & 42 & 91 & 72 \\
\hline
\end{tabular}


OSAS and 'PWI' ACTUAL to ACTUAL Domain Pattern ALL RESPONSES

\begin{tabular}{|c|c|c|c|c|}
\hline \multirow{2}{*}{$\begin{array}{c}\text { MAUT Place to } \\
\text { Work Pattern }\end{array}$} & \multicolumn{3}{|c|}{ OSAS ACTUAL Frequency Pattern by Overall Sample $(\mathrm{n}=411)$} \\
\cline { 2 - 5 } & $\begin{array}{c}\text { Control } \\
\text { Actual }\end{array}$ & $\begin{array}{c}\text { Affect } \\
\text { Actual }\end{array}$ & $\begin{array}{c}\text { Content } \\
\text { Actual }\end{array}$ & $\begin{array}{c}\text { Meaning } \\
\text { Actual }\end{array}$ \\
\hline & O-R & O-R & R-S & O-R-S \\
'Place to Work' & Integrity & Integrity-Citizenship & Integrity & Integrity \\
\hline
\end{tabular}

OSAS and 'PWI' ACTUAL to IDEAL Domain Pattern ALL RESPONSES

\begin{tabular}{|c|c|c|c|c|}
\hline \multirow{2}{*}{$\begin{array}{c}\text { MAUT Place to } \\
\text { Work Pattern }\end{array}$} & \multicolumn{3}{|c|}{ OSAS IDEAL Frequency Pattern by Overall Sample ( $\mathrm{n}=411)$} \\
\cline { 2 - 5 } & $\begin{array}{c}\text { Control } \\
\text { Ideal }\end{array}$ & $\begin{array}{c}\text { Affect } \\
\text { Ideal }\end{array}$ & $\begin{array}{c}\text { Content } \\
\text { Ideal }\end{array}$ & $\begin{array}{c}\text { Meaning } \\
\text { Ideal }\end{array}$ \\
\hline \multirow{2}{*}{$\begin{array}{c}\text { 'Place to Work' } \\
\text { Index ACTUAL }\end{array}$} & $\begin{array}{c}\text { O-R } \\
\text { Security }\end{array}$ & $\begin{array}{c}\text { C-S } \\
\text { Integrity }\end{array}$ & Integrity & C-S \\
Security-Integrity & & Integrity \\
\hline
\end{tabular}


Amanda L. Andrade was born in Phoenix, Arizona. After completing her undergraduate degree in Psychology from Ottawa University in 1996 she entered graduate school at Northern Arizona University receiving a Master's of Education degree in Counseling in 1999. In 2000, Ms. Andrade and her family relocated to Missouri to assist the State's Social Services in building organizational infrastructure and programs related to Human Resource Management. During her tenure she worked with a nationally acclaimed juvenile justice program that focused on environment and behavior based rehabilitation, with social service best practice initiatives with the Center for the Study of Social Policy, and partnered with the University of Missouri on management training initiatives for social workers. In 2004, Ms. Andrade was a recipient of the Governor's Torch of Excellence Award.

Ms. Andrade returned to the private sector in 2004 directing Human Resource programs. She obtained her SPHR, CCP and GRP professional designations and graduated from the University of Missouri-Columbia, receiving a Master's of Science in Architectural studies, with an emphasis on environment and behavior in the workplace. Ms. Andrade's academic focal point has been highly profitable, employee-centric work environments. Her research has focused on the attributes most commonly associated with outstanding work environments, leading to the development of the 'Place to Work' Index.

In 2012, Ms. Andrade accepted the role of Chief People Officer, President of Human Resources, for a company that is equally committed to promoting an 
employee-centric workplace. The company is one of the fastest growing in the United States according to INC magazine, was named in the top 50 Greatest Places to Work for mid-sized companies by Fortune magazine and received the Seal of Distinction for work/life balance employer for 2013. Address: $2101 \mathrm{~W}$. Broadway PMB263 Columbia, MO 65203 